\title{
L30A Mutation of Phospholemman Mimics Effects of Cardiac Glycosides on Isolated Cardiomyocytes
}

Ryan David Himes

Loyola University Chicago

Follow this and additional works at: https://ecommons.luc.edu/luc_diss

Part of the Physiology Commons

\section{Recommended Citation}

Himes, Ryan David, "L30A Mutation of Phospholemman Mimics Effects of Cardiac Glycosides on Isolated Cardiomyocytes" (2015). Dissertations. 1639.

https://ecommons.luc.edu/luc_diss/1639

This Dissertation is brought to you for free and open access by the Theses and Dissertations at Loyola eCommons. It has been accepted for inclusion in Dissertations by an authorized administrator of Loyola eCommons. For more information, please contact ecommons@luc.edu. (c) (i) $(9)$

This work is licensed under a Creative Commons Attribution-Noncommercial-No Derivative Works 3.0 License. Copyright @ 2015 Ryan David Himes 


\title{
LOYOLA UNIVERSITY CHICAGO
}

\author{
L30A MUTATION OF PHOSPHOLEMMAN \\ MIMICS EFFECTS OF CARDIAC GLYCOSIDES
}

ON ISOLATED CARDIOMYOCYTES

\author{
A DISSERTATION SUBMITTED TO \\ THE FACULTY OF THE GRADUATE SCHOOL \\ IN CANDIDACY FOR THE DEGREE OF \\ DOCTOR OF PHILOSOPHY
}

PROGRAM OF CELL AND MOLECULAR PHYSIOLOGY

BY

RYAN D. HIMES

CHICAGO, IL

AUGUST 2015 
Copyright by Ryan D. Himes, 2015

All Rights Reserved 


\section{ACKNOWLEDGEMENTS}

This work would not have been possible without the help of many people. My advisor, Dr. Seth Robia, helped me every step of the way. He and I conceived of the project idea together, and he spent countless hours training me in the techniques that I used, the data analysis, the presenting of data and the writing process. I greatly appreciated his patience with me, and his willingness to take time out of whatever he was working on at the time to answer my questions and provide assistance.

All of my lab colleagues deserve thanks for their support as well. In particular, Dr. Neha Abrol taught me how to perform functional myocyte assays, Dan Blackwell helped with cell culture and molecular cloning, and former technicians Alex Ticho and Chris Stefonowicz helped make some of the constructs used for this work.

I also want to thank all of my committee members: Dr. Allen Samarel (chairman), Dr. Sakthivel Sadayappan, Dr. Ken Byron, Dr. Jack Kaplan, and former members Dr. Renzhi Han and Dr. Graeme Carnegie. 


\section{TABLE OF CONTENTS}

ACKNOWLEDGEMENTS $\quad$ ii

LIST OF FIGURES $\quad$ vi

LIST OF ABBREVIATIONS Vi

ABSTRACT vii

CHAPTER ONE: HEART FAILURE, PLM, AND NKA

$\begin{array}{ll}\text { CHAPTER TWO: METHODS } & 18\end{array}$

CHAPTER THREE: RESULTS OF FRET AND FUNCTIONAL ASSAYS 27

CHAPTER FOUR: POTENTIAL THERAPEUTICS FOR HEART FAILURE

$\begin{array}{ll}\text { BIBLIOGRAPHY } & 62\end{array}$

$\begin{array}{ll}\text { VITA } & 71\end{array}$ 


\section{LIST OF FIGURES}

Figure $\quad$ Page

1. Mechanism of action of cardiac glycosides 14

2. Regulation of NKA activity 15

3. PLM binding equilibria 16

4. Fluorescently-labeled PLM and NKA 17

5. Fluorescent images of HEK cells 37

6. Effect of masking on images 38

7. Effect of masking on FRET data 39

8. PLM-NKA and PLM-PLM binding curves 40

9. KD values for PLM mutants 41

10. Fitting parameters for all binding curves 42

11. $\mathrm{K}_{\mathrm{D}} 2$ versus $\mathrm{K}_{\mathrm{D}} 1$ for each PLM mutant compared to WT 43

12. SBFI-based NKA activity assay 44

13. Ideal NKA activity curve derived from SBFI assay 45

14. Typical NKA activity curve derived from SBFI assay 46

15. Ouabain-sensitive ATPase activity of membrane preparations 47

16. Exogenous expression of PLM-Citrine in a myocyte 48

17. Examples of myocyte assay output 49

18. Functional myocyte data for WT PLM versus GFP 50 
19. Functional effects of PLM mutants in myocytes

20. WT-versus L30A-expressing myocytes in the presence of isoproterenol

21. $\mathrm{Ca}^{2+}$ transient data for WT versus L30A-expressing myocytes

22. Myocyte contraction data for WT versus L30A-expressing myocytes

23. Pharmacological versus physiological inhibition of NKA

61 


\section{LIST OF ABBREVIATIONS}

\begin{tabular}{ll} 
Ax594 & Alexa Fluor 594 \\
ECFP & enhanced cyan fluorescent protein \\
FRET & fluorescence resonance energy transfer \\
FWHM & full width at half maximum \\
GFP & green fluorescent protein \\
HEK & human embryonic kidney \\
HF & heart failure \\
NCX & sodium-calcium exchanger \\
NKA & sodium-potassium ATPase \\
PBS & phosphate buffered saline \\
PLB & phospholamban \\
PLM & phospholemman \\
SBFI & sodium-binding benzofuran isophthalate \\
SERCA & sarco/endoplasmic reticulum Ca ${ }^{2+}$-ATPase \\
SR & sarcoplasmic reticulum \\
TM & transmembrane \\
WGA & wheat germ agglutinin \\
WT & wild-type \\
\hline
\end{tabular}




\begin{abstract}
In order to determine if mutations made to phospholemman (PLM) could increase PLM binding to the Na/K-ATPase (NKA) and cause positive inotropy we performed scanning mutagenesis of the transmembrane domain of PLM and measured FRET between each mutant and NKA. We observed increased binding to NKA for several PLM mutants compared to WT, including L27A, L30A, and I32A. In isolated cardiomyocytes, overexpression of WT PLM increased the amplitude of the $\mathrm{Ca}^{2+}$ transient compared to GFP control. $\mathrm{Ca}^{2+}$ transient amplitude was further increased by L30A PLM overexpression. L30A mutation also delayed $\mathrm{Ca}^{2+}$ extrusion and increased the duration of the cardiomyocyte contraction. This mimics aspects of the effect of cardiac glycosides, which are known to increase contractility through inhibition of NKA. No significant differences between WT and L30A PLM overexpression were observed after treatment with isoproterenol, suggesting that the effects of L30A are reversible with $\beta$-adrenergic stimulation. The results implicate L30 as an important functional determinant and suggest that expression of L30A PLM could increase cardiac contractility while providing physiological reversibility of NKA inhibition.
\end{abstract}




\section{CHAPTER ONE}

\section{HEART FAILURE, PLM, AND NKA}

The heart plays a critical role in human physiology. It is the pump that provides blood flow to every cell in the body. The blood carries oxygen and nutrients to the cells, and also provides a means for cells to eliminate waste products and carbon dioxide. Without this constant perfusion of blood, cells and tissues die rapidly (Bers, 2002; McMurray \& Pfeffer, 2005; Mudd \& Kass, 2008). When the heart is not pumping properly and blood flow is insufficient to meet the demands of the body, the condition is known as heart failure (HF) (McMurray \& Pfeffer, 2005; Mozaffarian et al., 2015; Mudd \& Kass, 2008). This is one of the leading causes of morbidity and mortality around the world (McMurray \& Pfeffer, 2005; Mozaffarian et al., 2015).

The four main causes of HF are myocardial infarction (heart attack), defects with the valves of the heart, hypertension, and cardiomyopathies (diseases of the heart muscle) (McMurray \& Pfeffer, 2005; Mozaffarian et al., 2015). These conditions can either cause a weakening of the contraction strength of the heart (systolic HF), or a decrease in the ability of the heart to fill with blood between contractions (diastolic HF). Both types of HF can lead to symptoms such as fatigue, as well as pulmonary and peripheral edema. These symptoms can all contribute to the worsening of the HF condition, thus forming a dangerous "positive feedback 
loop" where the disease gets progressively worse over time. Without successful intervention, $\mathrm{HF}$ will result in death. Indeed, the disease is attributed as the underlying cause of death in nearly 60,000 cases per year in the US alone (Fuller et al., 2012; Hauptman \& Kelly, 1999; Mozaffarian et al., 2015; Yang, Shah, \& Criley, 2012).

There are various therapies available to treat HF. The oldest type of treatment is the class of drugs known as cardiac glycosides, which have been used for centuries (Bers, 2002; Fuller et al., 2012; Hauptman \& Kelly, 1999; Yang et al., 2012). Although their mechanism of action was unknown at first, now it is known that these drugs bind to and inhibit the action of the Na/K-ATPase (NKA) in heart muscle (Figure 1). NKA is responsible for extruding sodium from the cell after the propagation of the action potential (the electrical signal that travels throughout the heart and causes it to contract). Each action potential causes sodium to enter the cells, and NKA must rapidly pump the sodium back out again before the next action potential arrives (Bers, 2002; Lingrel, Argüello, Van Huysse, \& Kuntzweiler, 1997). When bound by cardiac glycoside, NKA is unable to extrude sodium, and so the intracellular sodium concentration, $\left[\mathrm{Na}^{+}\right]$, increases (see Figure 1) (Lingrel et al., 1997; Philipson \& Nicoll, 2000).

This rise in $\left[\mathrm{Na}^{+}\right]_{\mathrm{i}}$ leads to the reduction of $\mathrm{Ca}^{2+}$ extrusion by the sodiumcalcium exchanger (NCX; Figure 1) (Philipson \& Nicoll, 2000; Shattock et al., 2015). NCX normally transports sodium ions into the cell in exchange for calcium from the cytosol. However, when $\left[\mathrm{Na}^{+}\right]_{\mathrm{i}}$ is elevated, this sodium-calcium exchange activity is 
reduced, leading to a rise in $\left[\mathrm{Ca}^{2+}\right]_{\text {i. }} \mathrm{NCX}$ can even act in reverse when $\left[\mathrm{Na}^{+}\right]_{\mathrm{i}}$ is very high, transporting $\mathrm{Ca}^{2+}$ into the cell from the outside. Increased $\left[\mathrm{Ca}^{2+}\right]$ i leads to an increase in the strength of muscle cell contractions (also known as contractility) (Hauptman \& Kelly, 1999; Shattock et al., 2015; Yang et al., 2012). Therefore, by inhibiting NKA activity and causing a rise in $\left[\mathrm{Na}^{+}\right]_{i}$ and $\left[\mathrm{Ca}^{2+}\right]_{i}$, cardiac glycosides increase cardiac contractility, which can relieve the condition of HF.

However, cardiac glycosides can also be harmful if administered at too high of a dose (Hauptman \& Kelly, 1999; Homma, Amran, Nagasawa, \& Hashimoto, 2006; Yang et al., 2012). Overdose of these drugs leads to overload of $\left[\mathrm{Na}^{+}\right]_{\mathrm{i}}$, and overload of $\mathrm{Ca}^{2+}$ in the sarcoplasmic reticulum (SR), which is the main storage organelle for $\mathrm{Ca}^{2+}$ in muscle. When the SR is overloaded, $\mathrm{Ca}^{2+}$ can leak out, causing cells to contract at an inappropriate time. This is known as a delayed afterdepolarization, and occurs as $\mathrm{Ca}^{2+}$ is extruded by NCX, generating a positive inward current that can trigger another action potential throughout the heart. The outcome is often the generation of a cardiac arrhythmia (Homma et al., 2006; Yang et al., 2012). Arrhythmias compromise the ability of the heart to contract in a coordinated fashion and to generate optimal ejection of blood from the heart. Therefore, if the cardiac glycoside overdose is large enough to be arrhythmogenic, instead of improving cardiac output and relieving HF, it will actually worsen the health of the patient.

While every drug causes side effects and every drug has a limited range of effective concentrations, the therapeutic window for cardiac glycosides is especially 
narrow (Yang et al., 2012). Patients who are taking these drugs have their blood drawn sometimes on a daily basis to ensure that the drug concentration is high enough to be beneficial, but not so high as to be arrhythmogenic. If an overdose is administered, clearance from the blood is slow because the affinity of glycosides for NKA is quite high, and also the half-life is quite long (the half-life of digoxin is 20-50 hours) (Bossuyt et al., 2009; Cheung et al., 2010; Crambert, Fuzesi, Garty, Karlish, \& Geering, 2002; Yang et al., 2012). Doctors can use an anti-glycoside antibody in this case to help sequester the drug away from NKA and to aid in clearance. Because of their dangerously narrow therapeutic window, more and more physicians have been turning away from cardiac glycosides and are looking toward other options for treating HF, such as vasodilators which reduce cardiac afterload by decreasing systemic blood pressure.

I propose that a better way to treat HF may be to use a superinhibitory mutant form of the protein phospholemman (PLM). This 15-kDa protein was discovered to be an endogenous inhibitor of NKA in the heart in 2002 (Bossuyt et al., 2009; Cheung et al., 2010; Crambert et al., 2002; Despa et al., 2005). If a mutation to PLM causes it to bind to NKA with greater affinity than wild-type (WT) PLM, this could increase cardiac contractility through the same mechanism of action of cardiac glycosides, described above. However, the advantage to this approach for treating HF is that the cell can dynamically regulate the interaction of PLM with NKA by two physiological mechanisms. 
First, while cardiac glycosides prevent NKA from transporting $\mathrm{Na}^{+}$out of the cell, PLM reduces the affinity of NKA for $\mathrm{Na}^{+}$(Despa et al., 2005). This is depicted in Figure 2. Compared to the activity of NKA by itself, NKA bound by cardiac glycosides has a reduced maximal activity, or $\mathrm{V}_{\max }$. The degree to which glycosides reduce the $V_{\max }$ of NKA is dependent on the percentage of NKA molecules that are bound by the drug, which is directly proportional to the drug concentration. More drug causes a greater reduction in NKA activity, and a greater rise in $\left[\mathrm{Na}^{+}\right]_{\mathrm{i}}$ and $\left[\mathrm{Ca}^{2+}\right] \mathrm{i}$. At any given $\left[\mathrm{Na}^{+}\right]_{i}$, the activity of NKA is lower when the drug is applied than when it is absent. In contrast, the effect of PLM is not to change the $V_{\max }$ of NKA, but to shift the $\mathrm{K}_{0.5}$, or the $\left[\mathrm{Na}^{+}\right]_{i}$ at which NKA activity is half of $\mathrm{V}_{\max }$ (Bossuyt et al., 2009; Despa et al., 2005; Han, Tucker, Lingrel, Despa, \& Bers, 2009). The K0.5 is inversely proportional to the affinity of $\mathrm{NKA}$ for $\mathrm{Na}^{+}$; that is, a lower $\mathrm{K} 0.5$ means NKA has a greater affinity for $\mathrm{Na}^{+}$. PLM causes the $\mathrm{K}_{0.5}$ to increase, and the affinity of NKA for $\mathrm{Na}^{+}$to decrease. But PLM has little to no effect on $\mathrm{V}_{\max }$ (Bossuyt et al., 2009; Despa et al., 2005; Han et al., 2009). Therefore, at high $\left[\mathrm{Na}^{+}\right]_{\mathrm{i}}$, inhibition of NKA by PLM is overcome, $\mathrm{Na}^{+}$can be extruded, and $\mathrm{Na}^{+}$overload (and indirectly, $\mathrm{Ca}^{2+}$ overload) can be avoided. I propose that a superinhibitory PLM mutant could be a superior treatment for HF if it increases $\mathrm{K}_{0.5}$ more than WT PLM, without having an effect on $V_{\text {max. }}$

The second physiological mechanism by which the cell can relieve the inhibition of NKA by PLM is by phosphorylating PLM through $\beta$-adrenergic signaling (Despa et al., 2005; Han, Bossuyt, Martin, Despa, \& Bers, 2010). When the body is 
stressed, as in a fight-or-flight situation, epinephrine and norepinephrine are released into the bloodstream from the adrenal glands above the kidneys. These bind to $\beta$-adrenergic receptors on the outside of the heart and causes PLM to be phosphorylated through the signaling pathway of protein kinase A (Bossuyt, Despa, Martin, \& Bers, 2006; Despa et al., 2005; Han et al., 2010; Han, Bossuyt, Despa, Tucker, \& Bers, 2006; Khafaga et al., 2012). This causes relief of inhibition of NKA by PLM (Boguslavskyi et al., 2014; Bossuyt et al., 2006; Han et al., 2006; Khafaga et al., 2012; Q. Song, Pallikkuth, Bossuyt, Bers, \& Robia, 2011; Wypijewski et al., 2013), and this is also depicted in Figure 2. The $\mathrm{K}_{0.5}$ of NKA returns to the baseline value when PLM is phosphorylated, meaning NKA is able to more rapidly extrude sodium from the cell. This allows the heart to pump at a faster rate, enabling the individual to respond quickly to the physical threat that has triggered the fight-or-flight response. In the case of a superinhibitory PLM mutant, phosphorylation by PKA could allow the inhibition of NKA to be relieved if $\left[\mathrm{Na}^{+}\right]_{\mathrm{i}}$ or $\left[\mathrm{Ca}^{2+}\right]_{\mathrm{i}}$ becomes too high, assuming that the PLM mutant is still capable of being phosphorylated. Because of the physiological means by which the cell limits the inhibition of NKA by PLM, I predict that using a superinhibitory PLM mutant will be a superior treatment strategy for HF compared to the pharmacological approach of using cardiac glycosides.

It needs to be determined what mutation(s) of PLM will cause increased inhibition of NKA. I theorize that single alanine substitutions of PLM transmembrane domain residues would yield one or more superinhibitory mutants. 
The rationale behind this theory is based on the knowledge that monomeric PLM can either bind to NKA, or it can bind to itself and form homotetramers (see Figure 3) (Bers, 2002; Boguslavskyi et al., 2014; McMurray \& Pfeffer, 2005; Mudd \& Kass, 2008; Q. Song et al., 2011; Wypijewski et al., 2013). There two binding equilibria are linked, as PLM phosphorylation causes decreased binding of PLM to NKA and increased binding of PLM to PLM in tetramers (Beevers \& Kukol, 2006; 2007; McMurray \& Pfeffer, 2005; Mozaffarian et al., 2015; Mudd \& Kass, 2008; Q. Song et al., 2011). It is plausible, therefore, that a mutation that decreases PLM-PLM binding would increase the availability of free PLM monomer to bind to NKA. It is thought that the transmembrane domains of PLM mediate PLM-PLM binding (Beevers \& Kukol, 2006; 2007; McMurray \& Pfeffer, 2005; Mozaffarian et al., 2015; Palmer, Scott, \& Jones, 1991). There are several leucine and isoleucine residues in this domain that could mediate binding with the formation of leucine/isoleucine zippers (Cheung et al., 2010; McMurray \& Pfeffer, 2005; Mozaffarian et al., 2015; Palmer et al., 1991). Mutation of these residues to the smaller residue alanine could disrupt PLM tetramerization, and indirectly cause increased PLM-NKA binding, which could lead to a superinhibitory effect. The other advantage to mutating the transmembrane domain residues is that by leaving the residues of the cytosolic domain intact, the site of PLM phosphorylation is left undisrupted. This makes it likely that any candidate superinhibitory mutant would still be phosphorylatable, and therefore the superinhibition would be reversible by this mechanism. 
There are twenty residues in the transmembrane domain of PLM (Bidwell, Blackwell, Hou, Zima, \& Robia, 2011; Cheung et al., 2010; Fuller et al., 2012; Hauptman \& Kelly, 1999; Hou, Kelly, \& Robia, 2008; E. M. Kelly, Hou, Bossuyt, Bers, \& Robia, 2008; Mozaffarian et al., 2015; Palmer et al., 1991; Robia et al., 2007; Yang et al., 2012). Residue 24 is an alanine, so there are nineteen remaining residues that can be mutated to alanine and tested for superinhibitory potential. To screen these nineteen candidates in a reasonable timeframe, my advisor and I developed a fluorescence-based assay. Each PLM mutant was fused to the yellow fluorescent protein Citrine on the C-terminus of PLM (see Figure 4). These constructs were expressed (one at a time) in a cell line that stably expresses NKA tagged with enhanced cyan fluorescent protein (ECFP) on the N-terminus. I measured fluorescence resonance energy transfer (FRET) from ECFP to Citrine to quantify PLM-NKA binding. In the same cells, I also measured homotransfer FRET from Citrine to Citrine to quantify PLM-PLM binding. I hypothesized that PLM mutants that caused decreased PLM-PLM binding would also cause increased PLM-NKA binding. These mutants would be considered candidate superinhibitors and would be tested for functional effects on NKA activity and muscle cell contractility in later experiments. If a PLM mutant was found to be superinhibitory and to cause increased contractility, it could have the potential to be used clinically as a superior treatment for HF compared to cardiac glycosides. 
NKA and PLM: a review

In 1957, Jens Christian Skou discovered NKA, and for this work he received a share of the Nobel Prize in Chemistry (Fuller et al., 2012; SKOU, 1957). NKA is expressed in virtually every living organism (Fuller et al., 2012), and it hydrolyzes ATP to provide the necessary energy to remove three sodium ions from the cytosol in exchange for two potassium ions entering the cell. This has the net effect of reducing one positive charge within the cell for every pump cycle. NKA is a member of the P-type ATPase family, which is characterized by four structural domains (transmembrane, actuator, nucleotide-binding, and phosphorylation domains) and a phospho-enzyme intermediate state.

The affinity of NKA for $\mathrm{Na}^{+}$has been estimated to range from 9 to $19 \mathrm{mM}$, which is close to the resting $\left[\mathrm{Na}^{+}\right]_{\mathrm{i}}$ in the heart (Fuller et al., 2012). However, evidence suggests that NKA may be exposed to a sub-sarcolemmal pool of $\mathrm{Na}^{+}$that differs in concentration from bulk cytoplasmic $\mathrm{Na}^{+}$(Silverman, Warley, Miller, James, \& Shattock, 2003). Therefore, other transporters of $\mathrm{Na}^{+}$besides NKA (e.g. NCX) likely play an important role in regulating NKA activity by influencing this subsarcolemmal pool of $\mathrm{Na}^{+}$(Dostanic, Schultz, Lorenz, \& Lingrel, 2004).

In cardiac (as well as vascular smooth muscle) the two predominant isoforms of NKA are the $\alpha 1$ and $\alpha 2$ subunits, with $\alpha 3$ expression being relatively minor (Shattock et al., 2015). In cardiac muscle, evidence suggests that the $\alpha 2$ isoform is localized to the T-tubules, specifically near the junctional SR (Berry, Despa, Fuller, Bers, \& Shattock, 2007), whereas the $\alpha 1$ isoform is expressed throughout the 
sarcolemma. The functional implication of this is that the $\alpha 2$ subunit specifically regulates junctional sodium, and therefore calcium, and that this contributes to the regulation of muscle contraction. Indeed, evidence suggests that $\alpha 2$ in the heart is functionally coupled to NCX (P. F. James et al., 1999). However, $\alpha 1$ still influences cardiac excitation-contraction coupling as a global regulator of $\left[\mathrm{Na}^{+}\right]_{i}$ (Fuller et al., 2012). There are also three different isoforms of NKA $\beta$ subunits. These serve to help in trafficking of the $\alpha$ subunit to the plasma membrane (Fuller et al., 2012). In cardiac muscle, the principal $\beta$ isoform is $\beta 1$, although $\beta 3$ is also present (Tulloch et al., 2011). The principle FXYD protein expressed in the heart is PLM, although FXYD5 has also been detected in homogenates of whole hearts (Lubarski, PihakaskiMaunsbach, Karlish, Maunsbach, \& Garty, 2005).

PLM regulates both the $\alpha 1$ and $\alpha 2$ isoforms. Unphosphorylated PLM exerts tonic inhibition on the pump, and phosphorylation relieves this inhibition; however, phosphorylation does not completely abolish PLM-NKA binding (Bossuyt et al., 2006). It is not currently clear how PKA and PKC activity differentially influence $\alpha 1$ versus $\alpha 2$ activity. Inhibition of NKA alpha subunits is also mediated by posttranslational modifications. Palmitoylation and glutathionylation in response to oxidative stress result in inhibition of pump activity (Figtree et al., 2009; Howie, Tulloch, Shattock, \& Fuller, 2013).

For normal cardiac function, the trans-sarcolemmal sodium gradient must be maintained. But in the context of $\mathrm{HF},\left[\mathrm{Na}^{+}\right]$i has been shown to be elevated, and this is at least partially attributable to impaired NKA function and/or reduced NKA 
expression (Pogwizd, Sipido, Verdonck, \& Bers, 2003). Impaired NKA function may be due to the fact that PLM is hypophosphorylated in HF, which has been shown to contribute to worsening pathology (Boguslavskyi et al., 2014).

PLM was initially discovered in 1985 by Larry Jones and co-workers (Presti, Jones, \& Lindemann, 1985a). They showed that it is localized to the sarcolemma, and that it is phosphorylated in response to isoproterenol. Subsequent studies showed that it is also phosphorylated by PKC (Presti, Scott, \& Jones, 1985b) and that it is dephosphorylated by PP1 and PP2a (Neumann et al., 1999). In 1991, the protein was purified and its primary amino acid sequence was determined (Palmer et al., 1991). PLM is synthesized as a 92 residue pro-peptide, but the first 20 amino acids are then cleaved off, leaving a mature, 72 amino acid protein (Cheung et al., 2010). This has three domains: an N-terminal extracellular domain (which contains the FXYD motif), a transmembrane domain, and a C-terminal cytosolic domain, each of which are composed of $\alpha$-helices (Cheung et al., 2010). Various estimates put the basal phosophorylation of PLM at 25 - 46\% (Fuller et al., 2009; Silverman et al., 2005; Zhang et al., 2009).

In the year 2000, Kathy Sweadner found that PLM is a member of a larger family of FXYD proteins (Sweadner \& Rael, 2000). There are at least 12 members of this family of proteins, all of which contain an extracellular FXYD motif, a single transmembrane domain, and which regulate ion transport (Cheung et al., 2010). FXYD2 (also known as the gamma subunit of NKA) is expressed in the kidney (Sweadner \& Rael, 2000), and FXYD5 is present in HEK cells (Arystarkhova, Donnet, 
Muñoz-Matta, Specht, \& Sweadner, 2007). PLM is unique among the FXYD proteins, however, because of its conserved phosphorylation sites in the cytosolic domain (Fuller et al., 2012). It was originally proposed that these FXYD proteins oligomerized to form anion channels and to regulate cell volume (Moorman et al., 1995). But while subsequent studies proved that PLM does indeed form oligomers (Beevers \& Kukol, 2006; 2007; Bossuyt et al., 2006; 2009; Q. Song et al., 2011), various laboratories have failed to demonstrate an ion channel function for these oligomers (Fuller et al., 2012).

In 2002, Kaethi Geering showed for the first time that PLM coimmunoprecipitates with NKA $\alpha$ subunits (Crambert et al., 2002). NMR and X-ray crystallography suggest that the TM domain of FXYD proteins interacts with TM helices 2, 6 and 9 of NKA $\alpha$ subunits (Li et al., 2004; Lindzen, Gottschalk, Fuzesi, Garty, \& Karlish, 2006). It was later shown that PLM reduces the affinity of NKA for $\mathrm{Na}^{+}$and $\mathrm{K}^{+}$, while only minimally reducing $\mathrm{V}_{\max }$ (Crambert et al., 2002). Phosphorylation of PLM reverses these effects on NKA, allowing the heart to maintain the trans-sarcolemmal $\mathrm{Na}^{+}$gradient during sympathetic stimulation, thereby preventing $\mathrm{Na}^{+}$and $\mathrm{Ca}^{2+}$ overload and arrhythmogenesis (Despa, Tucker, \& Bers, 2008).

Phosphorylation of PLM has also been shown to cause inhibition of $\mathrm{Ca}^{2+}$ extrusion by NCX (Ahlers et al., 2005; Cheung et al., 2007; J. Song et al., 2012; J. Wang et al., 2006; Zhang et al., 2006). This is thought to help preserve inotropy while maintaining the trans-sarcolemmal $\mathrm{Na}^{+}$gradient during sympathetic 
stimulation (Cheung et al., 2010). However, another laboratory failed to detect a direct PLM-NCX interaction with co-immunoprecipitation or FRET (Bossuyt et al., 2006) so this theory has yet to gain broad acceptance in the field.

PLM has also been shown to interact with L-type $\mathrm{Ca}^{2+}$ channels in guinea pig myocytes and to alter their gating in HEK cells (X. Wang et al., 2010). PLM decreased the kinetics of activation and deactivation of these channels, and also increased the rate of voltage-dependent inactivation. In these studies, the FXYD motif was found to mediate these effects (Guo et al., 2010). However, whether PLM plays this role in the heart or if these observations were simply due to overexpression of PLM in HEK cells remains to be tested (Fuller et al., 2012). In addition to being phosphorylated, PLM can also be palmitoylated at its two cytosolic cysteine residues, $\mathrm{C} 40$ and C42 resulting in inhibition of NKA (Tulloch et al., 2011). These cysteines are well conserved, both among FXYD family members and across species (Cornelius \& Mahmmoud, 2003; Fuller et al., 2012). Therefore, palmitoylation may be a mechanism of regulation of NKA in tissues other than the heart. 


\section{Cardiac Glycosides}

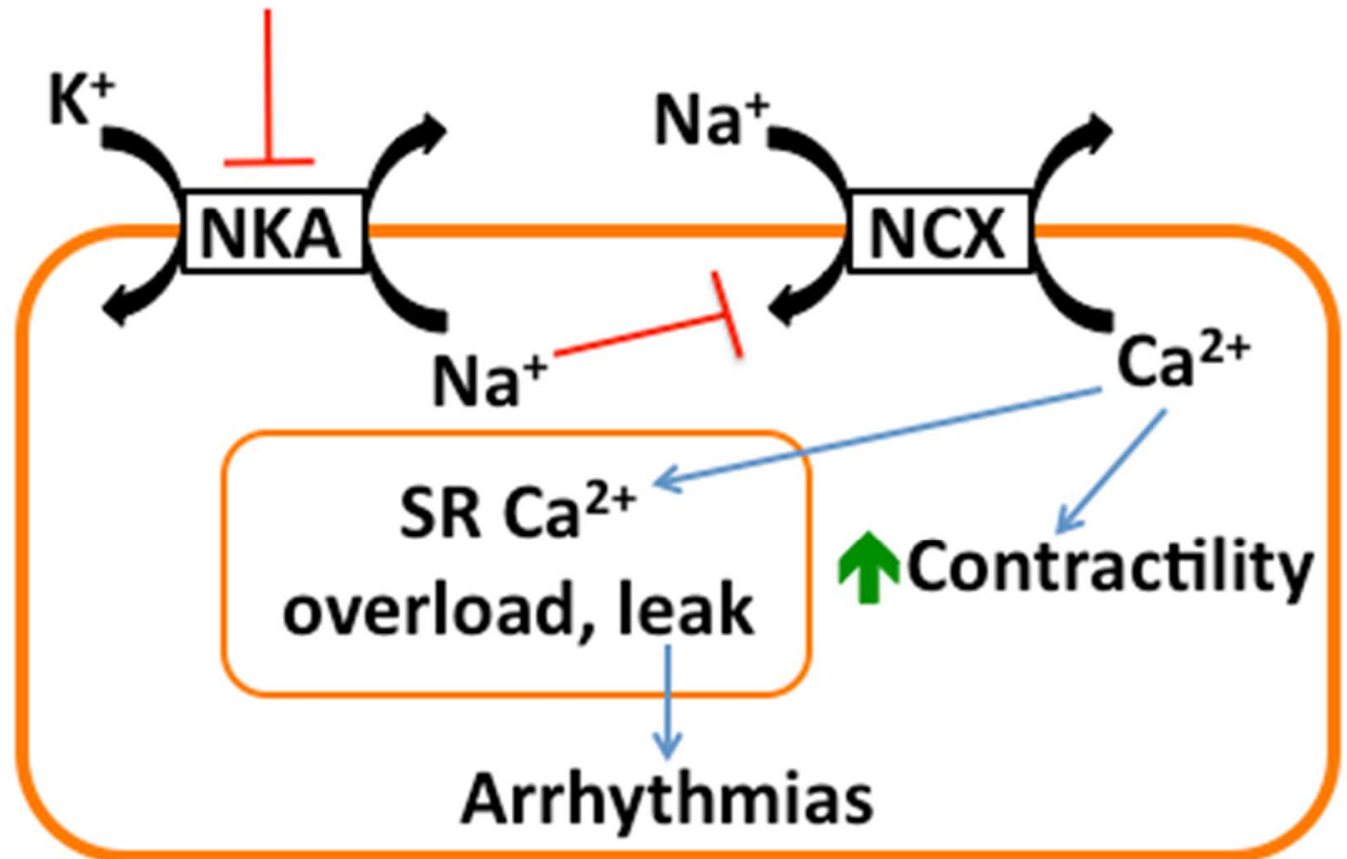

Figure 1. Mechanism of action of cardiac glycosides. Cardiac glycosides bind to and inhibit the action of NKA, resulting in a rise in $\left[\mathrm{Na}^{+}\right]_{i}$. This inhibits the action of NCX, leading to a rise in $\left[\mathrm{Ca}^{2+}\right]_{i}$ and increased contractility. However, overdoses of cardiac glycosides can lead to overload of $\mathrm{Ca}^{2+}$ in the $\mathrm{SR}, \mathrm{Ca}^{2+}$ leak, and arrhythmias. 


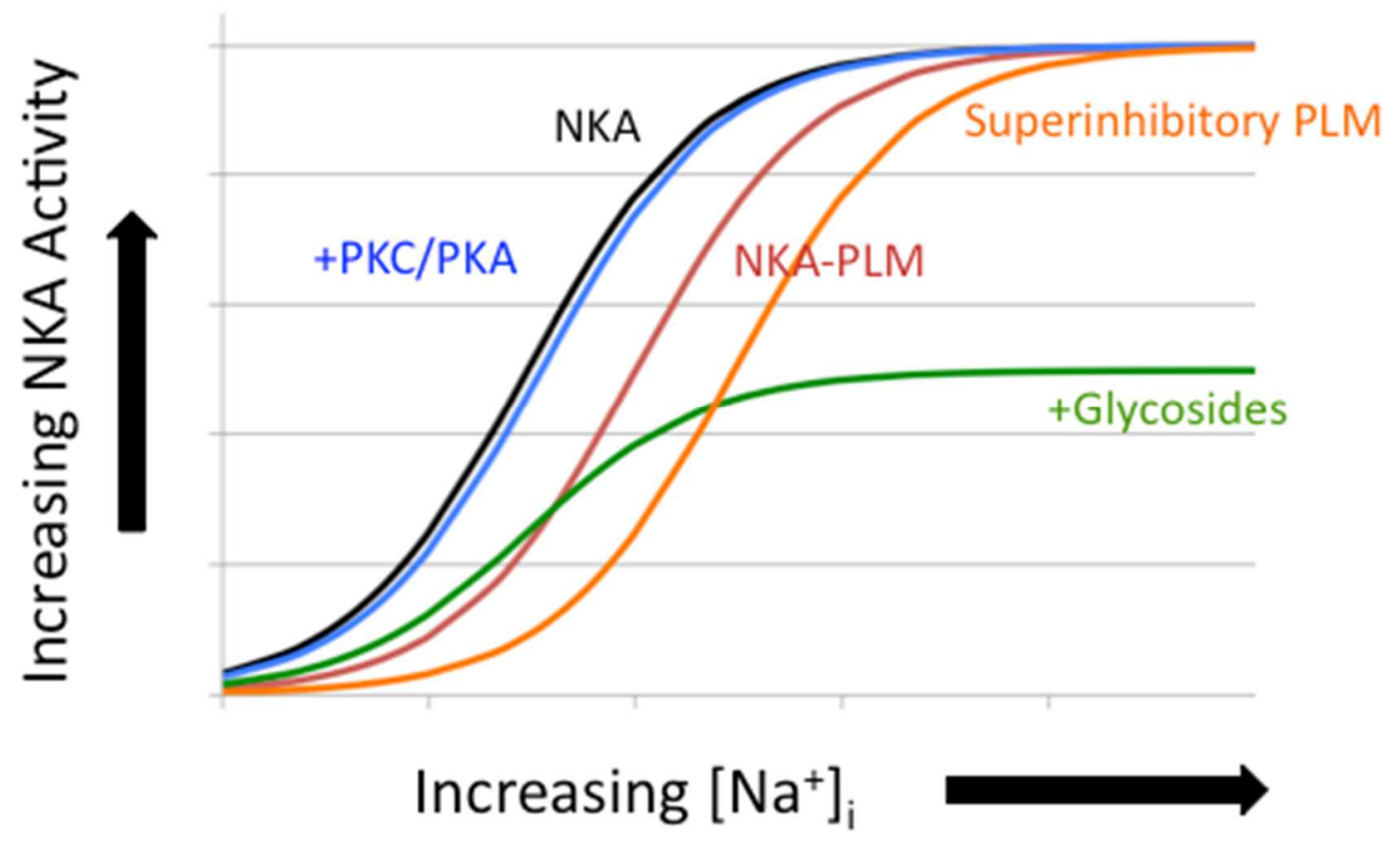

Figure 2. Regulation of NKA activity. The activity of NKA over a range of concentrations of intracellular $\mathrm{Na}^{+}$is depicted in black. The effect of cardiac glycosides in shown in green. Glycosides reduce $\mathrm{V}_{\max }$ for NKA. In red, the activity of NKA when bound by WT PLM is displayed, and the effect of PLM phosphorylation by PKA or PKC is shown in blue. PLM reduces the affinity of NKA for $\mathrm{Na}^{+}$, without changing $\mathrm{V}_{\text {max. }}$. Phosphorylation of PLM reverses this effect. The proposed regulation of NKA by a superinhibitory PLM mutant is shown in orange. It is hypothesized here that superinhibitory PLM will reduce the affinity of NKA for $\mathrm{Na}^{+}$to a greater extent than WT PLM, but that $\mathrm{V}_{\max }$ will remain unaffected. 


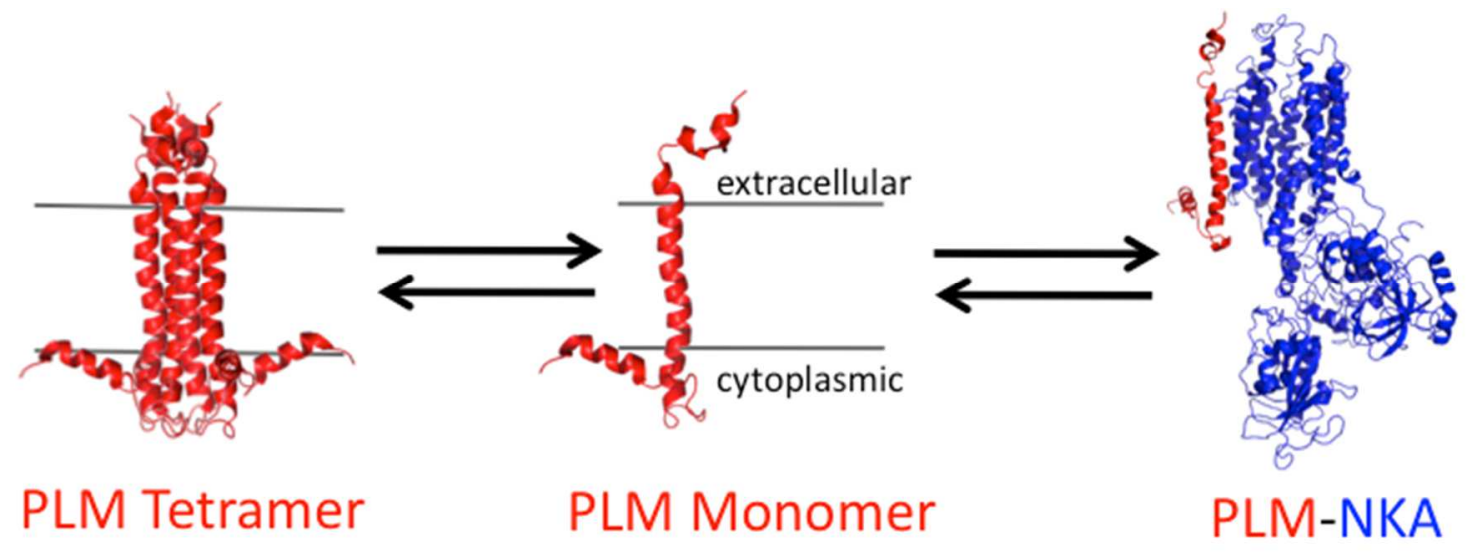

Figure 3. PLM binding equilibria. PLM monomer is capable of both binding to itself to form homotetramers and binding to NKA to form the PLM-NKA regulatory complex. Both of these complexes are thought to be in equilibrium with PLM monomers. 


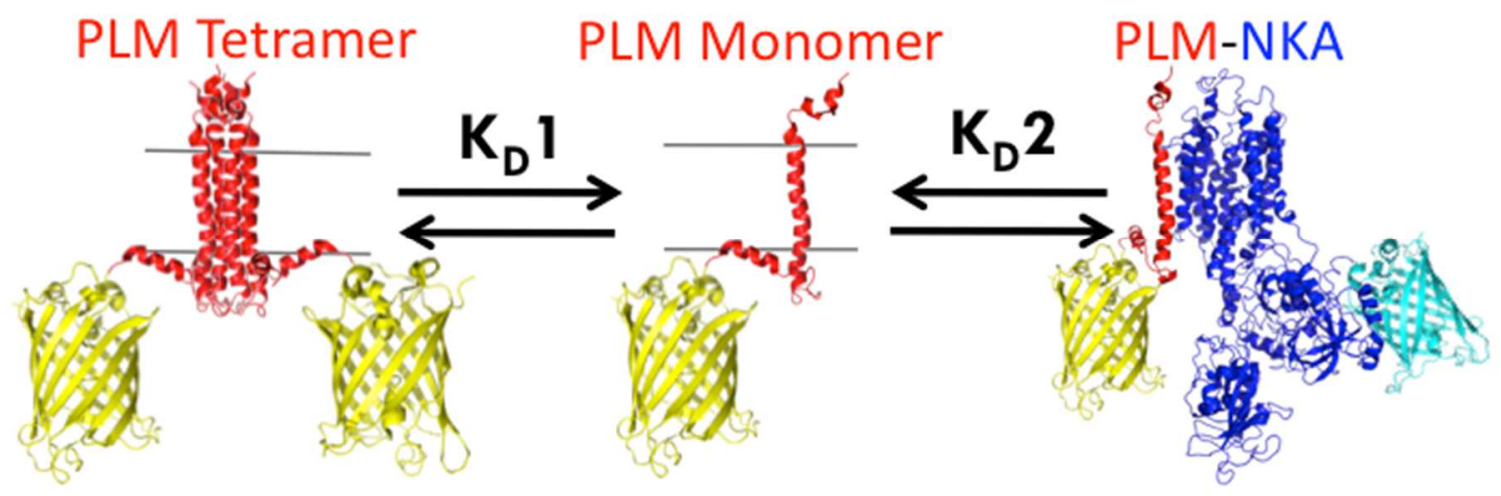

Figure 4. Fluorescently-labeled PLM and NKA. For the FRET assay in this study, PLM mutants were covalently attached to Citrine (depicted in yellow) and NKA was attached to ECFP (in light blue). Acceptor sensitization FRET was used to quantify the affinity of each mutant for binding to NKA, which is inversely proportional to $\mathrm{K}_{\mathrm{D}} 2$. Homotransfer FRET was used to quantify the affinity of each mutant for binding to itself, which is inversely proportional to $\mathrm{K}_{\mathrm{D}} 1$. 


\section{CHAPTER TWO}

\section{METHODS}

In this chapter, I will detail the FRET-based screening assay for the PLM mutants, as well as the experiments used to measure the effects of PLM mutation on NKA activity and on cardiomyocyte contractility.

\section{Molecular biology and cell culture}

In order to generate and screen PLM mutants for their superinhibitory potential, first canine WT PLM-Citrine plasmid was obtained from collaborators at the University of California, Davis: Drs. Julie Bossuyt and Donald Bers. This construct has a 19 amino acid linker between the C-terminus of PLM and the Nterminus of Citrine (Bers, 2002; Bossuyt et al., 2006; Fuller et al., 2012; Hauptman \& Kelly, 1999; Yang et al., 2012). Individual alanine mutations of the nineteen transmembrane domain residues were then made using site-directed mutagenesis. These constructs were used to express the Citrine-tagged PLM mutants in a stable NKA-ECFP cell line (Bers, 2002; Khafaga et al., 2012; Lingrel et al., 1997), and cells expressing both constructs were used to measure FRET and to quantify the PLMPLM and PLM-NKA binding interactions (described below). It should be noted that canine PLM differs from the human sequence in only four residues-three in the extracellular domain, and one in the transmembrane domain (in canines, valine 22 is an isoleucine). 
In order to express the PLM mutants in cardiac myocytes for contractility assays (described below) the constructs had to be inserted into adenoviruses, as these provide the most efficient means of expressing exogenous genes in myocytes. To accomplish this, the PLM-Citrine DNA was amplified using PCR and inserted into pShuttle vectors using restriction enzymes BamHI \& EcoRV. These vectors were then integrated into the adenoviral genome by Dr. Jody Martin using the AdEasy kit (Stratagene) (Abrol, de Tombe, \& Robia, 2015; Bidwell et al., 2011; Hou et al., 2012; Lingrel et al., 1997; Pallikkuth et al., 2013; Philipson \& Nicoll, 2000). All DNA sequences were verified by sequencing (ACGT, Inc.). Transient transfection of stable ECFP-NKA cell line

HEK-293 cells stably expressing ECFP tagged to the N-terminus of rat $\alpha 1$ NKA were cultured in Dulbecco's modified Eagle's medium with 10\% FBS until the day prior to imaging. Then cells were transferred to $60 \mathrm{~mm}$ culture dishes at a density of 250,000 cells per dish. 24 hours later, the cells were transfected with 1 $\mu g$ of either WT PLM-Citrine, or one of the mutants. Transfection was performed using Turbofect reagent ( $10 \mu \mathrm{L}$, ThermoFisher). The transfection solution was mixed and allowed to incubate at room temperature for 15 minutes before it was added to the cells.

Acceptor sensitization FRET and anisotropy measurements

Approximately 24 hours following transfection, the cells were trypsinized and transferred to 4-well glass-bottom chambers (MatTek) at a density of 150,000 cells per well. The cells were incubated for 90 minutes at $37^{\circ} \mathrm{C}$ in DMEM with $10 \%$ 
FBS to allow them to adhere to the bottom of the wells. They were then washed two times with PBS before imaging, followed by loading with $2 \mu \mathrm{g} / \mathrm{mL}$ wheat germ agglutinin (WGA) Alexa Fluor 594. This fluorescently-tagged lectin binds to cellsurface glycoproteins, and allows for FRET to be quantified exclusively at the plasma membrane of the cell, where the PLM-PLM and PLM-NKA binding interactions are relevant (this is described in further detail below). WGA was applied to the cells for three minutes, and then was washed three times with PBS.

Cells were imaged on a Nikon inverted microscope, using a 40X air objective. An acceptor sensitization FRET technique was used to measure binding between ECFP-NKA and each PLM-Citrine construct. For each acquisition field, a set of four images was taken to capture the fluorescence of ECFP, Citrine, FRET, and WGA Alexa Fluor 594, with exposure times of 2000, 50, 500, and 300 ms respectively. For the ECFP, Citrine, and WGA images, the specific fluorophore was excited and its emission was captured, whereas for the FRET image, ECFP was excited and Citrine emission was captured. Then the stage was automatically shifted so that a new field was in focus, and the imaging was repeated. In total, for each PLM construct 130 fields were imaged in rapid succession using automated stage movements. Focus on the cells was maintained using a perfect focus system (Nikon).

After these first four images were acquired for each field, the stage was reset back to the initial position, and image scanning was repeated, this time using polarization filters in order to measure fluorescence anisotropy of PLM-Citrine to quantify PLM-PLM binding. If the PLM-Citrine peptides are in close proximity in the 
membrane, homotransfer FRET can occur as one Citrine is excited and transfers energy to a neighboring Citrine (Blackman, Piston, \& Beth, 1998; Philipson \& Nicoll, 2000; Shattock et al., 2015). This energy transfer decreases the polarization of emitted fluorescence, and the depolarization is quantified as a decrease in fluorescence anisotropy. To measure the anisotropy of PLM-Citrine, vertically polarized excitation light (wavelength $=504 \mathrm{~nm}$ ) was used and then emission was captured with either a vertical (Iparallel) or a horizontal (Iperpendicular) polarizing filter in the emission light path. Both of these images were acquired with an exposure time of $1000 \mathrm{~ms}$.

For each field the WGA Alexa Fluor 594 image, which displayed fluorescence only at the plasma membrane of each cell, was used to generate a "mask" that was then applied to all other images. This was done using a no-neighbors deconvolution algorithm (Metamorph) performed on the WGA images. Masks of just the plasma membrane of each cell were then applied to all the other images in order to reduce the contribution of any intracellular expression of fluorescent protein constructs. This allowed us to calculate acceptor sensitization FRET and anisotropy solely at the plasma membrane, where PLM-NKA binding is relevant.

For each cell, acceptor sensitization FRET was calculated according to the formula:

FRET Efficiency $(\%)=$ $100 *$ (IFRET - alcitrine - dIECFP $) /\left(\right.$ IFRET - aICitrine - dIECFP $+\mathrm{G}^{*}$ IECFP $)$, 
where IFRET, ICitrine,, and IECFP are the average intensities of each cell in the FRET, Citrine, and ECFP images, respectively, 'a' is the acceptor cross-talk coefficient, 'd' is the donor bleed-through coefficient, and $\mathrm{G}$ is the ratio of sensitized emission to donor emission for a standard FRET construct (donor linked to an acceptor intramolecularly) (Hauptman \& Kelly, 1999; Shattock et al., 2015; Yang et al., 2012; Zal \& Gascoigne, 2004). The acceptor cross-talk coefficient was measured by imaging cells that only expressed Citrine (not ECFP), and then dividing the IFRET values by the $\mathrm{I}_{\text {Citrine }}$ values for those cells. Here it is crucial that the cells be imaged with the exact same experimental conditions that are used for the actual experiments. Similarly, the donor bleed-through coefficient was measured by imaging cells that only expressed ECFP and dividing the IFRET values by the IECFP values for those cells. $\mathrm{G}$ is measured by imaging cells expressing a donor-linked-toacceptor construct, in this case the blue fluorescent protein mCerulean linked to the yellow fluorescent protein mVenus by a 5 amino acid linker. The cells are imaged before and after destroying the mVenus with photobleaching, and G is calculated by the formula $\mathrm{G}=\left(\mathrm{I}_{\mathrm{FRET}}-\mathrm{aImVenus}-\mathrm{dI}\right.$ Cerulean $) /\left(\mathrm{I}_{\mathrm{mCerulean}}-\mathrm{I}_{\mathrm{mCerulean}}\right)$, where $\mathrm{I}_{\mathrm{mCerulean}}$ is the post-bleach ImCerulean. For the experiments performed in this manuscript, $\mathrm{a}=$ $0.091, d=0.83$, and $G=4.6$.

Anisotropy was calculated according to the formula: $r=\left(I_{\text {parallel }}-\mathrm{I}_{\text {perpendicular }}\right) /\left(\mathrm{I}_{\text {parallel }}+2 \mathrm{I}_{\text {perpendicular }}\right)$, where $\mathrm{r}$ is the average anisotropy of each cell. 
Calculation of PLM-PLM and PLM-NKA binding affinities

Once the average acceptor sensitization and anisotropy for each cell was calculated, these data were plotted against each cell's PLM-Citrine expression as an index of exogenous PLM concentration, in arbitrary units (Hauptman \& Kelly, 1999; Homma et al., 2006; Hou \& Robia, 2010; Yang et al., 2012). These types of plots can be used to quantify the binding affinity of a protein-protein interaction, because FRET efficiency is proportional to the extent of binding of the proteins. By fitting these plots with Hill functions, a dissociation constant ( $\mathrm{or} \mathrm{K}_{\mathrm{D}}$ ) can be calculated for each binding interaction in order to quantify the affinity. Lower $K_{D}$ values correspond to greater affinity of binding. Here, the data were fit with the following Hill functions.

For acceptor sensitization FRET:

FRET Efficiency $(\%)=c+\left(\left(\text { FRET }_{\max }-\mathrm{c}\right)^{*}\left[\right.\right.$ Protein $\left.^{\mathrm{n}}\right) /\left(\mathrm{K}_{\mathrm{D}} 2^{\mathrm{n}}+\left[\right.\right.$ Protein $\left.^{\mathrm{n}}\right)$, where $\mathrm{c}$ is the FRET of the unbound fluorescent proteins, and FRETmax is the FRET of the fully bound regulatory complex; $n$ is the Hill coefficient, and [Protein] is the average intensity of the Citrine for each cell in arbitrary units, taken to be an index of the concentration of PLM. $K_{D} 2$ is the dissociation constant for the PLM-NKA binding interaction.

For anisotropy:

Anisotropy $(\mathrm{r})=\mathrm{r}_{0}+\left(\left(\mathrm{r}_{\mathrm{n}}-\mathrm{r}_{0}\right)^{*}[\text { Protein }]^{\mathrm{n}}\right) /\left(\mathrm{K}_{\mathrm{D}} 1^{\mathrm{n}}+[\text { Protein }]^{\mathrm{n}}\right)$, where $\mathrm{n}$ is the Hill coefficient, $r_{0}$ is the inherent anisotropy of unbound fluorescent proteins, and $r_{n}$ is the anisotropy of the fully bound PLM tetramer. $\mathrm{K}_{\mathrm{D}} 1$ is the dissociation constant 
for the PLM homotetramer. Fitting was performed with Origin software. For each mutant PLM, four separate binding curves from four different transfections were globally fit together, sharing all parameters except for $K_{D}$. These four pairs of $K_{D}$ values were then averaged together and plotted with their associated SEM. Myocyte cell culture and functional assays

In order to test the effect of PLM mutations on cardiac function, mutants were expressed in isolated rabbit ventricular myocytes. The rabbit PLM sequence is $>95 \%$ identical to the canine sequence, and there is precedence for using exogenous canine proteins in isolated rabbit myocytes (Abrol et al., 2015; Homma et al., 2006; Yang et al., 2012). Fusing these mutants to Citrine did not interfere with localization of the exogenous proteins to the sarcolemma and T-tubules, as is shown in the next section (Figure 16). These myocytes were isolated by Jollyn Tyryfter as described in published literature (Domeier, Blatter, \& Zima, 2009; Yang et al., 2012). Once isolated, cells were pipetted into a $50 \mathrm{~mL}$ conical tube and allowed to settle for 5-10 minutes until pelleted. The supernatant was drawn off, and then the cells were reconstituted in $5 \mathrm{~mL}$ of PC-1 medium (Lotran, Inc.). This was repeated two more times. Then cells were transferred to laminin-coated $14 \mathrm{~mm}$ cover slips (MatTek) and incubated for one hour. Adenoviruses containing the DNA sequences for the WT or mutant PLM-Citrine constructs were added to the cells at a multiplicity of infection of 500 virus particles per cell (Bossuyt et al., 2009; Cheung et al., 2010; Crambert et al., 2002; Pallikkuth et al., 2013; Yang et al., 2012). Dish volumes were brought up to $2 \mathrm{~mL}$ with PC-1 medium and cells were incubated and paced at $10 \mathrm{~V}, 5$ 
ms pulse duration, $0.1 \mathrm{~Hz}$ overnight (Bossuyt et al., 2009; Cheung et al., 2010;

Crambert et al., 2002; Despa et al., 2005; Pallikkuth et al., 2013). Pacing was performed so that the T-tubules would remain intact throughout the culture period. Effects of PLM mutants were compared to WT, which was used consistently as a control throughout the experiments. That is, on any given experimental day, cells isolated from a single rabbit were split into two groups, and one group was infected with WT virus, while the other group was infected with a PLM mutant.

After $\sim 18$ hours of incubation cells were visualized using confocal microscopy in order to observe the expression and localization of the PLM-Citrine. Then, the cells were washed twice with Tyrode solution and were loaded with 10 $\mu \mathrm{M}$ Indo-1 AM for 20 minutes. This $\mathrm{Ca}^{2+}$-binding dye acts as an index of $\left[\mathrm{Ca}^{2+}\right]_{\mathrm{i}}$, as its fluorescence intensity ratio increases with increasing $\left[\mathrm{Ca}^{2+}\right]$ i (Molecular Devices). The ratio is calculated by exciting the dye at $\lambda=340 \mathrm{~nm}$ and measuring emission at $\lambda$ $=405$ and dividing by emission at $\lambda=485 \mathrm{~nm}$. Finally, cells were washed three times with Tyrode solution, and measurements were made with cells in the presence of either Tyrode solution alone, or $20 \mathrm{nM}$ isoproterenol in Tyrode solution. $20 \mathrm{nM}$ isoproterenol was used because a higher concentration of $100 \mathrm{nM}$ (Abrol et al., 2015; Despa et al., 2005) caused the vast majority of myocytes to contract in a dysrhythmic fashion. The ED50 of isoproterenol on $\beta$-adrenergic receptors is approximately $50 \mathrm{nM}$ (Bossuyt et al., 2009; Despa et al., 2005; Han et al., 2009; J. R. Miller, Silver, \& Stull, 1983; Y. Takuwa, Takuwa, \& Rasmussen, 1988). 
Myocytes were stimulated to contract using $30 \mathrm{~V}, 2$ ms duration pulses, and $0.5 \mathrm{~Hz}$ frequency (Bossuyt et al., 2009; Despa et al., 2005; Han et al., 2009; Pallikkuth et al., 2013). Myoctes were measured only if they were not touching other cells, were contracting longitudinally, and were adhered to the laminin-coated cover slip in such a way that they could contract without coming off of the glass substrate. Using an IonOptix system, the average length of the sarcomeres of each cell was measured to quantify cell shortening (and contractility). This was done by drawing a region of interest around a set of sarcomeres, approximately ten sarcomeres in length, and one sarcomere wide. Sarcomeres were identified visually by a clear pattern of alternating light and dark "stripes" on the image of the myocyte. At the same time, Indo-1 fluorescence was measured within a region of interest that was drawn around the cell at rest. The fluorescence intensity ratio $\mathrm{F}$ was measured as described above, and was normalized to $\mathrm{F}_{0}$, the ratio at time $=0 \mathrm{sec}$. Ten contractions were measured for each myocyte, and the resulting traces were averaged together and fit using IonOptix software. I was blinded to the identity of the myocyte samples while making measurements.

\section{Statistics}

All data are plotted as mean \pm SEM. All mutant data were compared to WT using Student's unpaired T-test, with significance being noted at $\mathrm{p}<0.05$. 


\section{CHAPTER THREE}

\section{RESULTS OF FRET AND FUNCTIONAL ASSAYS}

In order to measure the effects of PLM mutations on PLM-PLM and PLM-NKA binding, Citrine-tagged PLM mutants were transiently transfected into a stable cell line expressing ECFP-NKA, and a combination of homotransfer and heterotransfer FRET assays were performed on the cells. Figure 5 displays the typical fluorescence that was observed for ECFP-NKA, PLM-Citrine, and the plasma membrane stain WGA Alexa Fluor 594. All three of these images were acquired in the same exact field. Comparing the NKA image to the WGA image, I observed that nearly $100 \%$ of the cells expressed the exogenous NKA. Expression was mostly localized to the plasma membrane, with some fluorescence also being observed in the perinuclear region. The Citrine image shows that approximately $50 \%$ of the cells expressed the exogenous PLM, and that these cells also expressed the protein in the plasma membrane and perinuclear region.

In contrast to the ECFP and Citrine fluorescence, the WGA Alexa Fluor 594 fluorescence was much more localized to the plasma membrane (i.e., there was very little Alexa Fluor 594 fluorescence observed within the interior of the cell). Because of this, the WGA images could be used to generate a plasma membrane mask that was applied to all the other images in each field. Then, the image analysis software (Metamorph) could quantify the fluorescence underneath the mask for each cell. In 
Figure 6, the effect of masking is observed on an ECFP image of a cell. With masking, the contribution of the perinuclear fluorescence to the overall measured fluorescence in the cell is reduced. This allowed for the calculation of FRET in the area of the cell where the PLM and NKA binding interactions are most relevant.

For each PLM mutant, many transfected cells were imaged, and the average acceptor sensitization FRET at the plasma membrane was calculated. These values were plotted against the average Citrine intensity of each cell, which was used as an index of the concentration of PLM. A representative graph is displayed in Figure 7, before and after the WGA mask was used. Each of these data sets were fit with the Hill function described in the previous chapter. Figure 7 shows that the WGA mask reduced the variability in the data, and the correlation coefficient for the fit improved from 0.61 to 0.78 .

The same cells that were imaged to measure PLM-NKA binding (using the acceptor sensitization FRET assay) were also imaged to measure PLM-PLM binding (using the anisotropy assay). The average anisotropy at the plasma membrane of each cell was plotted against the average Citrine intensity. A pair of PLM-NKA and PLM-PLM binding graphs for WT PLM are shown in Figure 8.

In order to calculate the $K_{D} 1$ and $K_{D} 2$ values for each PLM mutant, data from four separate biological replicates (transfections) were generated. Each biological replicate yielded a pair of anisotropy and acceptor sensitization binding curves. These were then globally fit using Origin software and the Hill functions described in the previous chapter. For anisotropy curves, all of the fitting parameters were 
shared for each mutant, except for the KD1 parameter. That is, the four binding curves from the four biological replicates were fit together using global fitting, assuming that the $r_{0}, r_{n}$, and Hill coefficients were the same among the four replicates, but allowing $\mathrm{K}_{\mathrm{D}} 1$ to vary. This allowed for the measurement of the variance in $\mathrm{K}_{\mathrm{D}} 1$ among biological replicates. Similarly, for acceptor sensitization curves, all of the fitting parameters where shared for each mutant, except for the $\mathrm{K}_{\mathrm{D}} 2$ parameter. The average $\mathrm{K}_{\mathrm{D}}$ values \pm SEM for each mutant are shown in Figure 9. The fitting parameters are displayed in Figure 10.

Figure 9 compares the $\mathrm{K}_{\mathrm{D}}$ values for each PLM mutant to WT (and a blue dashed line has been drawn for reference). For $K_{D} 1$, mutants that had lower values than WT are considered more tetrameric, because KD values are inversely proportional to the affinity of binding. The first mutant displayed after WT is the phosphomimetic S63E/S68E PLM, which was found to be significantly more oligomeric than WT. This is in agreement with previous results from the Robia lab and other groups which showed that PLM phosphorylation increases tetramerization (Boguslavskyi et al., 2014; Despa et al., 2005; Han et al., 2010; Q. Song et al., 2011; Wypijewski et al., 2013). In contrast, non-phosphorylatable mutant S63A/S68A was more oligomeric than the phosphomimetic, and was not significantly different from WT. All of the transmembrane domain alanine substitution mutants displayed robust homotransfer FRET. While the KD1 values of several mutants were not significantly different from WT, five mutants (I18A, I23A, 
I26A, G31A and L33A) were significantly more oligomeric. One mutant, L30A, was less oligomeric, with a KD1 value approximately four-fold greater than WT.

In Figure 9, mutants with $\mathrm{K}_{\mathrm{D}} 2$ values less than WT are considered gain of NKA binding mutants; those with values greater than WT are loss of binding. I observed significantly increased PLM-NKA binding for non-phosphorylatable PLM. Phosphomimetic PLM displayed decreased affinity for NKA binding, and this approached statistical significance $(p=0.067)$. These results were as predicted based on previous studies (Bossuyt et al., 2006; Despa et al., 2005; Han et al., 2006; 2010; Khafaga et al., 2012; Q. Song et al., 2011). These previous studies had led me to hypothesize that $\mathrm{K}_{\mathrm{D}} 2$ was dependent on $\mathrm{K}_{\mathrm{D}} 1$. That is, PLM modifications that increased $K_{D} 1$ would also decrease $K_{D} 2$, and vice versa. However, while this relationship was true for phosphomimetic and non-phosphorylatable PLM, it was not true for most of the transmembrane domain mutants. Instead, many of the mutants (I23A through S37A) displayed increased PLM-NKA binding regardless of the effect on oligomerization. I22A was the only mutant that had a significantly increased $\mathrm{K}_{\mathrm{D}} 2$ compared to WT.

Figure 11 displays these same $K_{D} 1$ values on the $x$-axis, and $K_{D} 2$ values on the $\mathrm{y}$-axis, \pm SEM. As mentioned above, no clear dependence of $\mathrm{K}_{\mathrm{D}} 2$ on $\mathrm{K}_{\mathrm{D}} 1$ is observed. This is in contrast to what was observed for another membrane transporter, SERCA, and its small peptide regulator, PLB (Boguslavskyi et al., 2014; Bossuyt et al., 2006; Han et al., 2006; Khafaga et al., 2012; Kimura, Kurzydlowski, Tada, \& MacLennan, 1997; Q. Song et al., 2011; Wypijewski et al., 2013). Indeed, it was these findings 
from SERCA/PLB, along with the results of studies on PLM phosphorylation, that contributed to the hypothesis that the dependence of $\mathrm{K}_{D} 2$ on $\mathrm{K}_{\mathrm{D}} 1$ would be true for transmembrane domain PLM mutants as well. The only mutant for which that was the case was $\mathrm{L} 30 \mathrm{~A}$, which had an increased $\mathrm{K}_{\mathrm{D}} 1$ value and a decreased $\mathrm{K}_{\mathrm{D}} 2$. Still, the main goal of this study was to find superinhibitory PLM mutants, and all of the mutants that displayed increased PLM-NKA binding were considered candidate superinhibitors. Several of these mutants were tested for functional effects on NKA activity and myocyte contractility. I chose mutants L27A, L30A, and I32A, because these showed some of the largest gains in NKA binding affinity.

PLM mutants that displayed increased NKA binding were hypothesized to also cause increased NKA inhibition. This hypothesis was tested using several different assays of NKA activity. However, none of them ended up being successful. The first assay that was attempted involved the use of the sodium binding fluorescent dye SBFI to measure [Na+] (Despa, Islam, Pogwizd, \& Bers, 2002; Khafaga et al., 2012). As with the FRET assays, HEK cells expressing ECFP-NKA were transiently transfected with PLM-Citrine mutants, and then were loaded with SBFI. The fluorescence ratio of SBFI was monitored while cells were loaded with $\mathrm{Na}^{+}$using an external solution without $\mathrm{K}^{+}$. Without $\mathrm{K}^{+}$as a counter-ion, NKA is unable to maintain the $\mathrm{Na}^{+}$gradient across the cell membrane, and so internal $\left[\mathrm{Na}^{+}\right]$ gradually equilibrates with external $\left[\mathrm{Na}^{+}\right]$. Then, the external solution is rapidly switched to a $4 \mathrm{mM} \mathrm{K}^{+}$solution without $\mathrm{Na}^{+}$, activating $\mathrm{NKA}$ and causing $\left[\mathrm{Na}^{+}\right]_{\mathrm{i}}$ to rapidly decline. Finally, the cells are brought to known concentrations of $\left[\mathrm{Na}^{+}\right] \mathrm{i}$ 
using standard solutions in order to calibrate the SBFI fluorescence to $\left[\mathrm{Na}^{+}\right]$i. An example of one of these experiments is shown in Figure 12. In order to calculate NKA activity over a range of $\left[\mathrm{Na}^{+}\right]_{i}$ values, the negative of the derivative of the $\mathrm{Na}^{+}$ extrusion portion of the data is calculated, and plotted against the $\left[\mathrm{Na}^{+}\right]_{\mathrm{i}}$ value of each point. A graph of this type is displayed in Figure 13, fit with a Hill function as described in Chapter Two.

The problem with this assay was that the data were usually far more variable than the examples shown in Figures 12 and 13, which were from the experiments with the least amount of variability. Usually, the activity curves that were generated failed to show a saturation of NKA activity. See Figure 14 for a more representative example. Without saturation, it is difficult to measure the effects of PLM mutations on NKA activity, as it is impossible to calculate $V_{\max }$ or the affinity of NKA for $\mathrm{Na}^{+}$. I also tried replacing SBFI with another dye that was purported to yield more consistent results, Asante Natrium Green (TefLabs). However, the fluorescence spectra of this dye overlap greatly with the spectra of Citrine (the peak excitation wavelength for Asante is $517 \mathrm{~nm}$, versus $516 \mathrm{~nm}$ for Citrine). Since my PLM mutants were all tagged to Citrine, the signal to noise ratio of Asante fluorescence was very low, making these experiments even more variable than the previous ones. Lastly, I attempted to measure the ouabain-sensitive ATPase activity of membranes from cells overexpressing the PLM mutants (this experiment was performed in conjunction with Rebecca Clifford from the laboratory of Dr. Jack Kaplan at the University of Illinois at Chicago). Ouabain, a cardiac glycoside, inhibits 
NKA activity (Laursen, Gregersen, Yatime, Nissen, \& Fedosova, 2015; Lingrel et al., 1997). Therefore by measuring the total ATPase activity at baseline and then subtracting the activity measured in the presence of saturating ouabain, the NKAspecific ATPase activity can be calculated (Ishizuka, Fielding, \& Berlin, 1996). To test the viability of the experiment, I transfected HEK cells with either WT PLMCitrine, or untagged GFP as a control. The cells overexpressing PLM-Citrine displayed fluorescence at the plasma membrane, while the GFP cells displayed fluorescence throughout the cytoplasm. This fluorescence was even observable by the naked eye after the membranes were isolated: for the PLM-overexpressing cells, only the membrane fraction was fluorescent, while for the GFP-overexpressing cells, only the cytosolic fraction was fluorescent. These qualitative observations confirmed that the membrane preparation procedure worked properly.

However, when testing the membranes for ouabain-sensitive ATPase activity, again a great deal of variability was observed. This is seen in Figure 15. Furthermore, no significant difference was detected between PLM overexpression versus the GFP control. This made it unlikely that subtle shifts in the $\mathrm{Na}^{+}$-binding affinity of NKA due to PLM mutations would be resolvable using this assay.

It was at this point that I decided to abandon attempts at directly measuring NKA activity, and moved on to testing for functional effects of PLM mutants on cardiomyocytes. Cardiomyocytes isolated from rabbits were cultured and infected with adenoviruses to overexpress WT or mutant PLM-Citrine. WT PLM was used as a control each day that infections were performed, so as to be able to compare all 
other mutants to WT using cells isolated from a single rabbit (i.e., one rabbit was used for each experimental day, and cells from that rabbit were infected with separately infected with WT and a mutant form of PLM). After 24 hours of exposure to virus, exogenous PLM expression was observed using confocal microscopy, as shown in Figure 16. The WGA Alexa Fluor 594 stain was used here to label the plasma membrane of the cardiomyocytes. As with expression in the HEK cell line, Citrine fluorescence was observed in the perinuclear region as well as in the sarcolemma and transverse tubulues where it co-localized with WGA.

After observing the expression and localization of the exogenous PLM constructs, the cardiomyocytes were electrically paced. Both $\left[\mathrm{Ca}^{2+}\right]$ i and its effect on sarcomere shortening were measured simultaneously in cells overexpressing either untethered GFP (control), WT PLM, or a mutant form of PLM. I was blinded to the sample identity for these experiments. An example of the output is shown in Figure 17. Each electrical stimulus caused a rapid influx of $\mathrm{Ca}^{2+}$ and shortening of the sarcomeres, followed by extrusion of calcium and cell relaxation. Approximately 10 stimuli were measured and then averaged together for each cell.

Figure 18 displays the average $\left[\mathrm{Ca}^{2+}\right]_{\mathrm{i}}$ and sarcomere length traces for GFPvs. WT PLM-overexpressing myocytes. I observed a significant increase in the amplitude of the $\mathrm{Ca}^{2+}$ transient for WT PLM compared to the control, as well as significantly delayed kinetics of $\mathrm{Ca}^{2+}$ handling. These results were similar to what was previously observed when treating isolated rabbit cardiomyocytes with ouabain (a cardiac glycoside) in culture (Altamirano et al., 2006; Bers, 1987; 2002; 
Bers \& Bridge, 1988). This suggests that NKA in these myocytes is not saturated by endogenous PLM, and that overexpression of WT PLM in these cells is increasing PLM-NKA binding. Furthermore, this increased binding possibly causes increased inhibition of NKA activity, as the observed phenotype mimicked that of a known NKA inhibitor.

Next, I compared the effects of the PLM mutants L27A, L30A, and I32A to WT. Again, WT was used for comparison because it was tested on every single experimental day, so that mutants could be compared to WT using cells isolated from the same rabbit. While L27A and I32A displayed no significant effects on $\mathrm{Ca}^{2+}$ handling or cell shortening, L30A caused a significant increase in the amplitude of the $\mathrm{Ca}^{2+}$ transient, as well as in the kinetics of $\mathrm{Ca}^{2+}$ handling and cell shortening. The effects of L30A were significantly greater in magnitude than the effects of WT PLM overexpression (compared to the GFP control). This suggests that, as was observed with the FRET assay, L30A PLM causes increased binding to NKA compared to WT, and it is likely that this results in increased inhibition of NKA (although I was unable to test that directly). These results are summarized in Figure 19.

Finally, I tested the effect of isoproterenol on the function of cardiomyocytes overexpressing L30A versus WT PLM, to see whether they could respond to adrenergic stress. Isoproterenol is structurally similar to epinephrine and is a $\beta$ adrenergic receptor agonist., known to lead to protein kinase A phosphorylation of many target proteins, including PLM (Bers, 2002). As expected, $20 \mathrm{nM}$ isoproterenol treatment resulted in large inotropic and lusitropic effects on all cells 
tested (see Figure 20). Interestingly, no differences between WT and L30Aoverexpressing cells could be observed after treatment with isoproterenol. The broadening of the $\mathrm{Ca}^{2+}$ transient by L30A PLM was no longer apparent after $\beta$ adrenergic stimulation.

All of the $\mathrm{Ca}^{2+}$ handling and cell shortening parameters for WT versus L30A PLM are displayed in Figures 21 and 22.

The results of all experiments are discussed in the following chapter. 


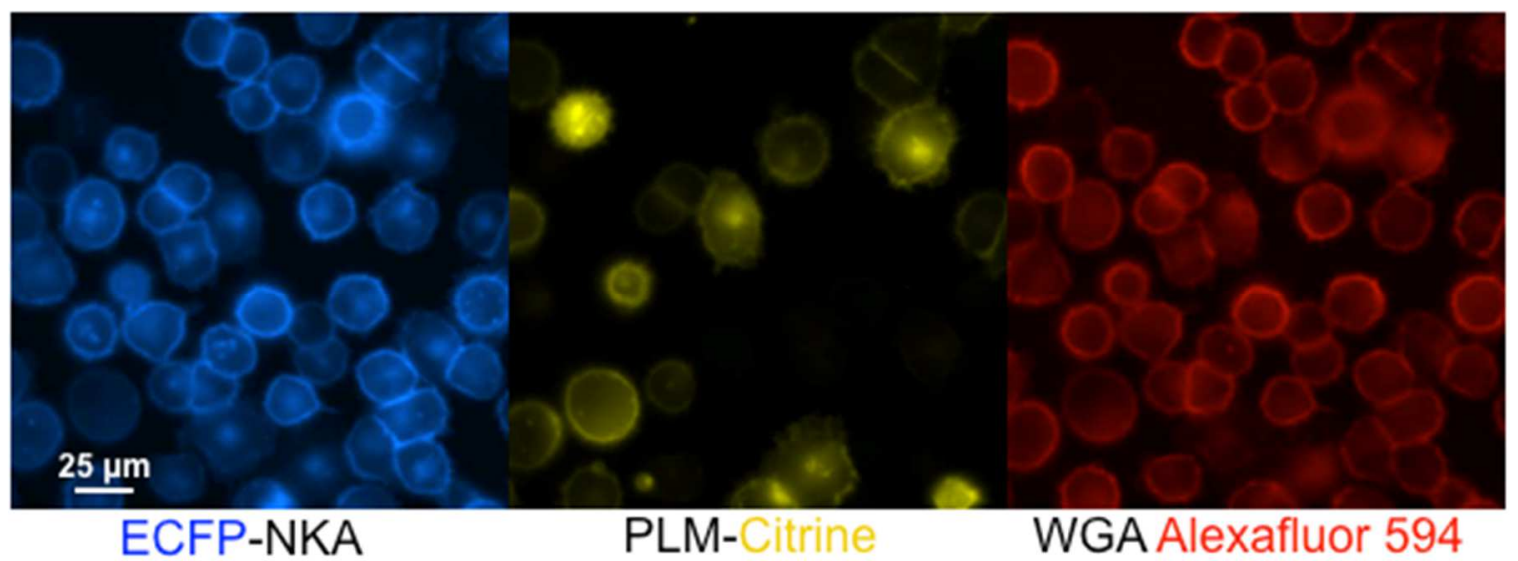

Figure 5. Fluorescent images of HEK cells. The three images above were all acquired in the same field. On the left, the fluorescence of cells that stably express ECFP-NKA is shown in blue. These cells were transfected with PLM mutants tagged to Citrine, shown in yellow in the middle panel. The cell membranes were also stained with WGA Alexafluor 594, shown in red on the right. 


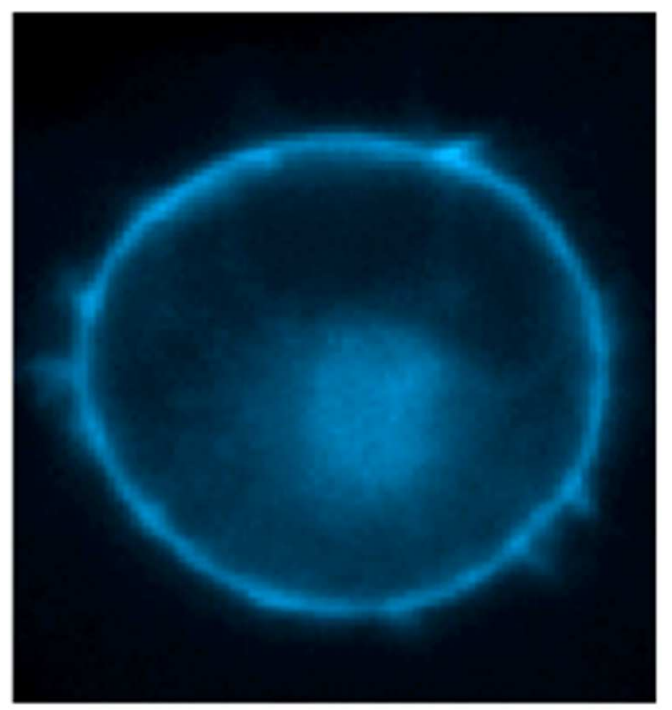

Raw Image

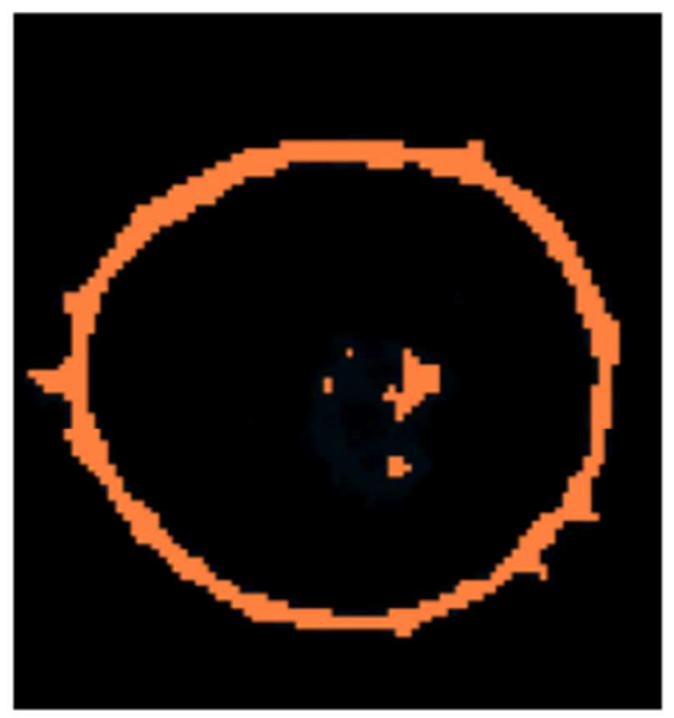

Masked Image

Figure 6. Effect of masking on images. On the left, a typical HEK cell expressing ECFP-NKA is displayed. Fluorescence can be observed in a plasma membrane and perinuclear pattern. After applying the plasma membrane mask, generated from the WGA Alexa Fluor 594 image, and performing the deconvolution algorithm, the resulting image is shown in orange on the right. Compared to the left, the intracellular fluorescence is greatly reduced after masking. 
Whole cell average:

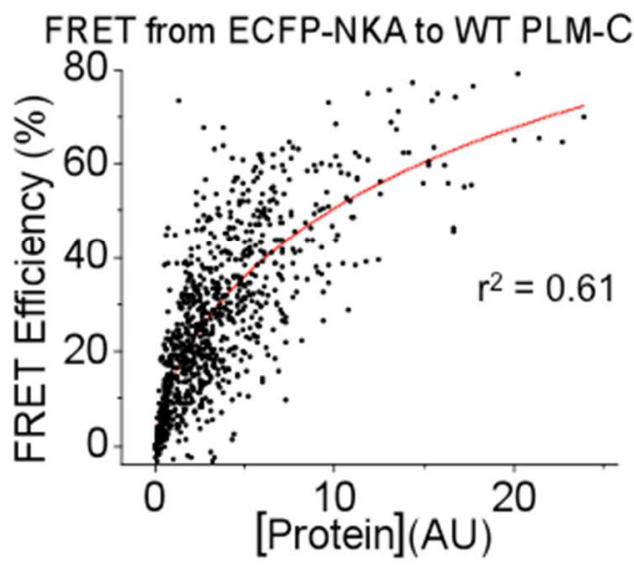

Plasma membrane only:



Figure 7. Effect of masking on FRET data. The graphs above display the average FRET efficiency from cells co-expressing ECFP-NKA and WT PLM-Citrine, plotted against the average Citrine intensity of each cell as an index of PLM concentration. Data are shown before (left) and after (right) the plasma membrane mask was applied to the images. Data were fit with a Hill function, and the resulting correlation coefficients are displayed. 

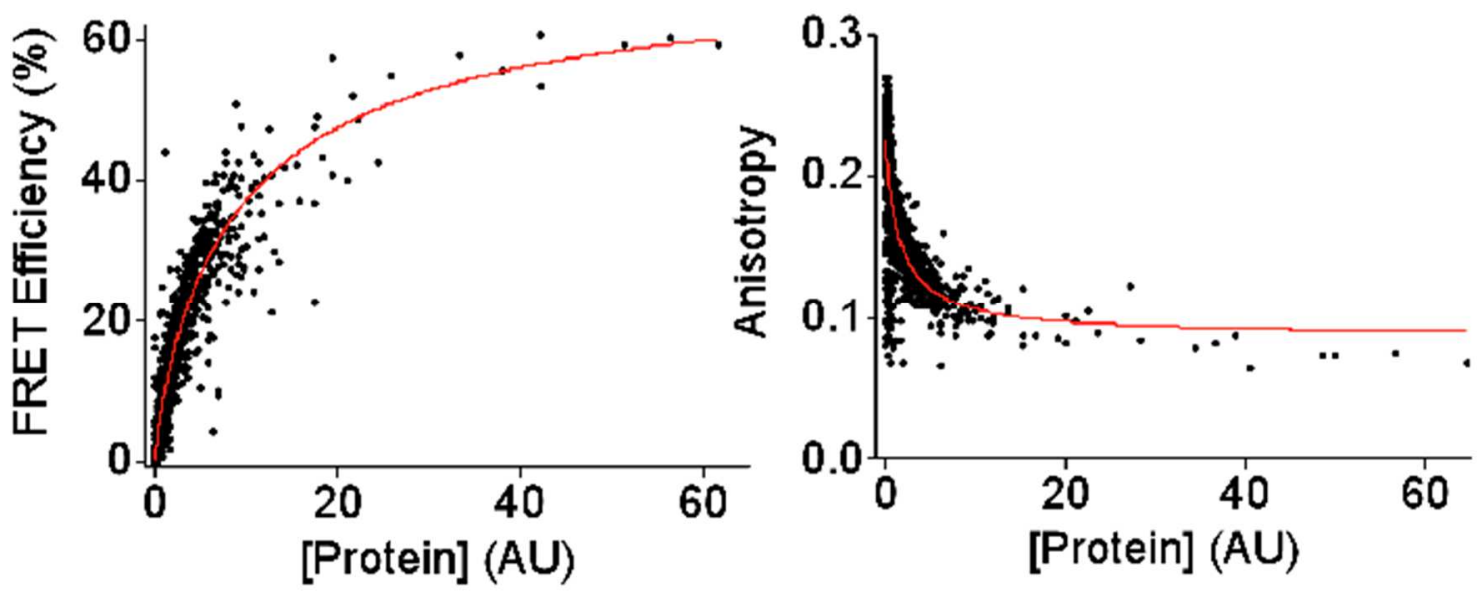

Figure 8. PLM-NKA and PLM-PLM binding curves. On the left, WT PLM-NKA FRET is plotted against the average Citrine intensity of each cell, as an index of PLM concentration. On the right, the average anisotropy of each cell is plotted against the same. The data sets have been fit with Hill functions. 

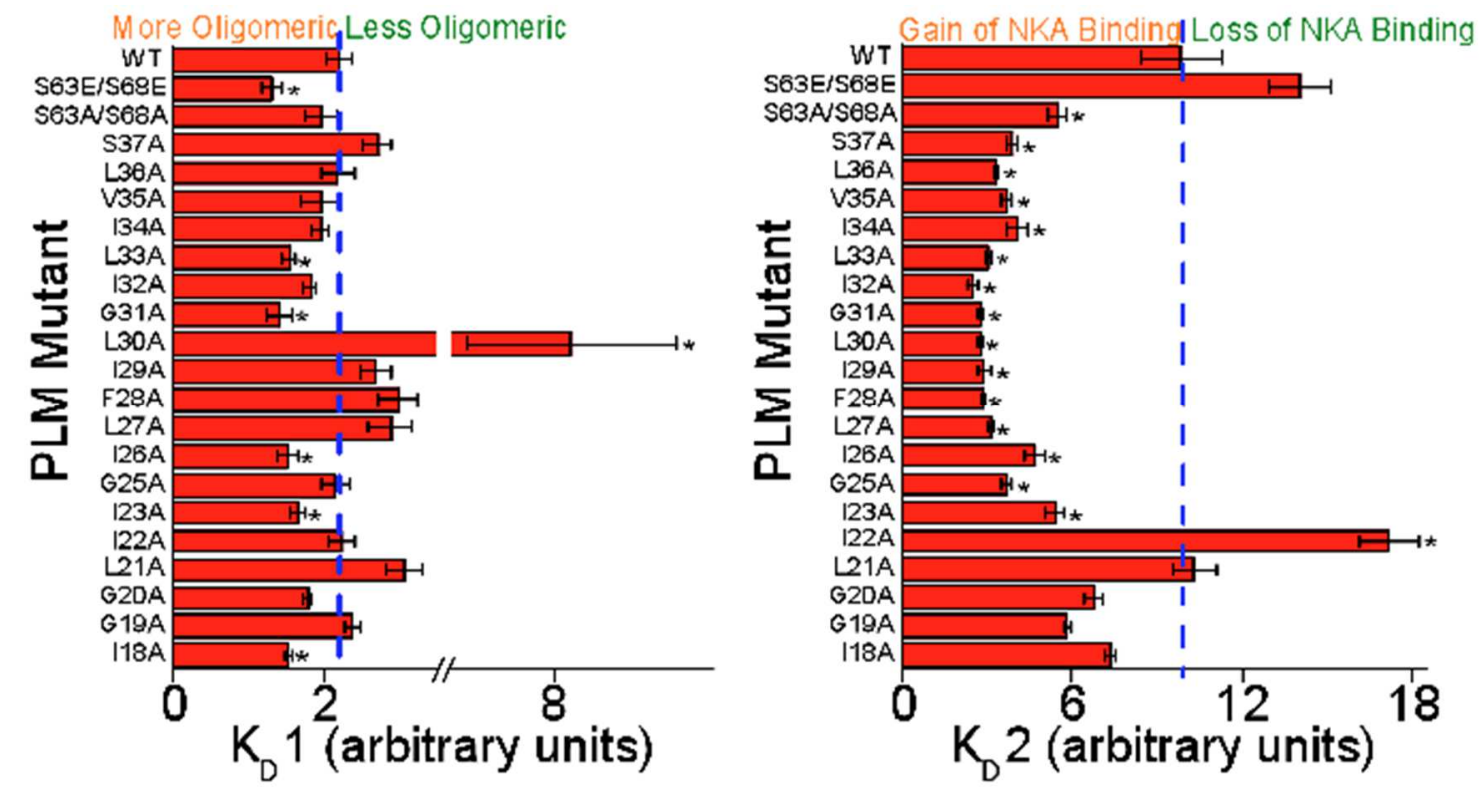

Figure 9. KD values for PLM mutants. The KD1 values \pm SEM (left) for each PLM mutant are compared to WT (blue dashed line). Mutants with $\mathrm{K}_{\mathrm{D}} 1$ less than WT are considered more oligomeric. $\mathrm{K}_{\mathrm{D}} 2$ values \pm SEM are also compared to WT (right), and mutants with $\mathrm{K}_{\mathrm{D}} 2$ values less than WT are considered gain of NKA binding mutants. $\mathrm{N} \geq 4$ biological replicates. ${ }^{*} \mathrm{p}<0.05$ compared to WT by Student's T-test. 


\begin{tabular}{|c|c|c|c|c|c|c|c|c|c|c|c|c|c|}
\hline & $\underline{r_{t}}$ & & $\underline{r_{n}}$ & n & & $b_{0} 1$ & & n & $\varepsilon(\%)$ & FRET $_{\text {max }}(\%)$ & $i_{0} 2$ & & $\mathrm{n}$ \\
\hline VT & $2 \pm$ & 0 & \pm & 0 & \pm & \pm 0 & $20 \pm$ & \pm 0 & $-0.8 \pm 0.3$ & $54.7 \pm 2.1$ & $9.9 \pm 1.4$ & 0.79 & \pm 0.03 \\
\hline & $53 \pm$ & 0 & $067 \pm$ & & & \pm 0. & $70 \pm$ & \pm 0 & $-0.1 \pm 0$ & $58.9 \pm 2.1$ & $14.0 \pm 1.1$ & 0.75 & \pm 1 \\
\hline & $71 \pm$ & 0 & $0.052 \pm$ & $=0$ & $96=$ & \pm 0. & $.51=$ & \pm 0. & $0.7 \pm 0$. & $44.4 \pm 0.7$ & $5.5 \pm 0.3$ & 1.00 & \pm 0.02 \\
\hline $1 \mathrm{~A}$ & & 0 & $064 \pm$ & 0.0 & $9 \pm$ & \pm 0 & $80 \div$ & \pm 0 & $6 \pm 0$ & $5.2 \pm 1.4$ & $3.9 \pm 0.2$ & 1.00 & \pm 0 \\
\hline & $45 \pm$ & 004 & $061 \pm$ & 0.0 & $16 \pm$ & \pm 0.2 & $68 \pm$ & \pm 0.0 & $0.6 \pm 0$. & $32.7 \pm 0.8$ & $3.3 \pm 0.1$ & 1.13 & \pm 0.0 \\
\hline & $234 \pm$ & 0.004 & $0.066 \pm$ & 0.005 & $1.94 \pm$ & \pm 0.25 & $0.67 \pm$ & \pm 0.06 & $0.6 \pm 0.3$ & $9.3 \pm 1.7$ & $3.7 \pm 0.2$ & 1.01 & \pm 0.05 \\
\hline A & $215 \pm$ & 0.002 & $0.089 \pm$ & 0.004 & $1.94=$ & \pm 0.12 & $1.12=$ & \pm 0.0 & $1 \pm 0.2$ & $0.9 \pm 1.3$ & $4.0 \pm 0.3$ & 1.05 & \pm 0.04 \\
\hline L33A & \pm & 03 & \pm & $t$ & $2 \pm$ & \pm & \pm & \pm & $4 \pm$ & $3 \pm 0.7$ & $0 \pm 0.1$ & 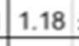 & \pm 0.03 \\
\hline $2 A$ & $232 \pm$ & 0.001 & $0.082 \pm$ & 0.004 & $1.80=$ & \pm 0.09 & $1.07 \pm$ & \pm 0.05 & $0.7 \pm 0.1$ & $28.3 \pm 0.4$ & $2.5 \pm 0.2$ & 1.40 & \pm 0.04 \\
\hline G31A & $0.263 \pm$ & 0.003 & $0.081 \pm$ & 0.000 & $1.41=$ & \pm 0.17 & $0.67 \pm$ & \pm 0.02 & $1.4 \pm 0.1$ & $22.6 \pm 0.7$ & $2.8 \pm 0.1$ & 1.41 & \pm 0.06 \\
\hline L30A & $0.287 \pm$ & 0.015 & $-0.044 \pm$ & 0.003 & $8.20=$ & \pm 1.18 & $0.35=$ & \pm 0.07 & $1.4 \pm 0.2$ & $20.9 \pm 0.7$ & $2.7 \pm 0.1$ & 1.22 & \pm 0.00 \\
\hline $9 \mathrm{~A}$ & $251 \pm$ & 0.006 & $0.048 \pm$ & 0.019 & $2.67 \div$ & \pm 0.22 & $0.59 \pm$ & \pm 0.07 & $.7 \pm 0.2$ & $8.8 \pm 0.8$ & $2.9 \pm 0.2$ & 1.35 & \pm 0.07 \\
\hline F28A & $0.214 \pm$ & 0.002 & $0.085 \pm$ & 0.007 & $2.97 \div$ & \pm 0.26 & $1.00 \pm$ & \pm 0.09 & $1.2 \pm 0.3$ & $30.8 \pm 0.8$ & $2.8 \pm 0.1$ & 1.23 & \pm 0.07 \\
\hline $27 \mathrm{~A}$ & $0.236 \pm$ & 0.003 & $0.067 \pm$ & 0.012 & 2.87 & \pm 0.30 & $0.79 \pm$ & \pm 0.08 & $0.9 \pm 0.2$ & $23.9 \pm 0.9$ & $3.1 \pm 0.1$ & 1.12 & \pm 0.07 \\
\hline $6 \mathrm{~A}$ & $0.272 \pm$ & 0.006 & $0.063 \pm$ & 0.018 & $1.52=$ & \pm 0.13 & $0.65=$ & \pm 0.08 & $1.1 \pm 0.1$ & $6.0 \pm 1.8$ & $4.7 \pm 0.4$ & 1.04 & \pm 0.05 \\
\hline $5 \mathrm{~A}$ & $244 \pm$ & 0.004 & $0.073 \pm$ & 0.011 & $2.13 \pm$ & \pm 0 & $0.71 \pm$ & \pm 0.07 & $0.9 \pm 0.1$ & $31.8 \pm 0.8$ & $3.7 \pm 0.2$ & 1.08 & \pm 0.04 \\
\hline & $257 \pm$ & 0.003 & $0.084 \pm$ & 0.008 & $1.65=$ & \pm 0.1 & $0.79 \pm$ & \pm 0.0 & $0.8 \pm 0.1$ & $40.1 \pm 1.0$ & $5.4 \pm 0.3$ & 1.09 & \pm 0.02 \\
\hline & $265 \pm$ & 0.004 & $0.055 \pm$ & 0.014 & $2.22=$ & \pm 0.1 & $0.62 \pm$ & \pm 0.0 & $0.0 \pm 0.1$ & $58.9 \pm 2.8$ & $17.2 \pm 1.1$ & 0.77 & \pm 0.02 \\
\hline L21A & $258 \pm$ & 0.005 & $0.047 \pm$ & 0.024 & $3.04=$ & \pm 0. & $0.60=$ & \pm 0. & $0.6=0.1$ & $.1 \pm 2.1$ & $10.3=0.8$ & 0.97 & \pm 0.03 \\
\hline 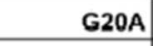 & $0.249 \pm$ & 0.003 & $0.072 \pm$ & 0.008 & $1.77 \pm$ & \pm 0.0 & $0.76 \div$ & \pm 0. & $0.3 \pm 0.1$ & $46.3 \pm 1.6$ & $6.8 \pm 0.3$ & 0.98 & \pm 0.03 \\
\hline 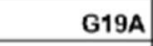 & $0.235 \pm$ & 0.002 & $0.075 \pm$ & 0.006 & $2.36=$ & \pm 0.10 & $0.85 \pm$ & \pm 0. & $0.4 \pm 0.1$ & $42.8 \pm 0.8$ & $5.8 \pm 0.1$ & 1.01 & \pm 0.02 \\
\hline BA & $298 \pm$ & 0.010 & $0.039 \pm$ & 0.028 & $1.52:$ & \pm 0.0 & $0.53 \pm$ & \pm 0. & $0.6 \pm 0$ & $49.4 \pm 1$ & $7.3 \pm 0.2$ & 1.02 & 0. \\
\hline
\end{tabular}

Figure 10. Fitting parameters for all binding curves. The complete set of all fitting parameter values is displayed for each PLM mutant, \pm SEM. $N \geq 4$ biological replicates. 


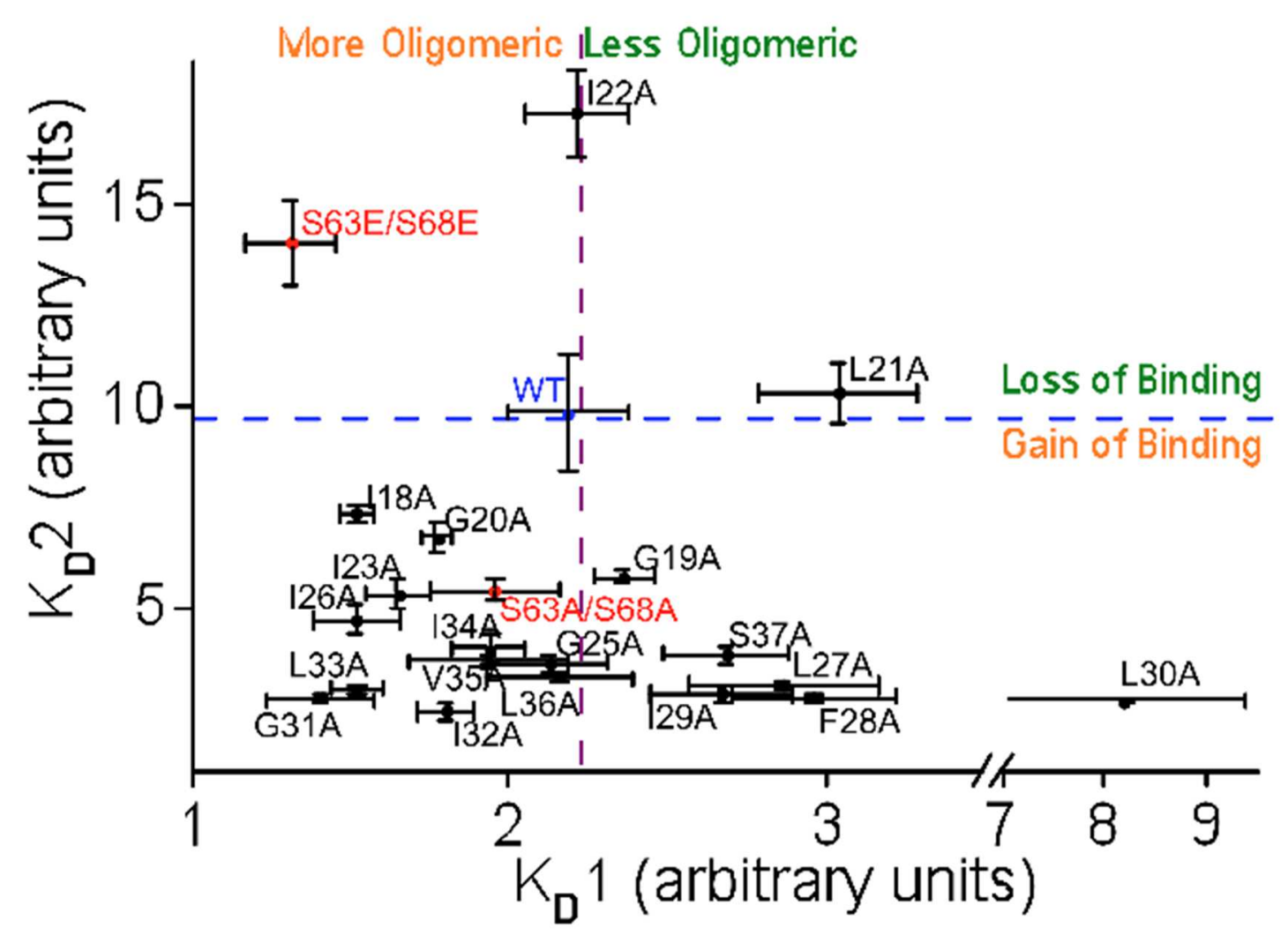

Figure 11. KD2 versus $K_{D} 1$ for each PLM mutant compared to WT. The KD2 value for each mutant is plotted against its $K_{D} 1$ value, \pm SEM. The blue and purple dashed lines are used as a reference to WT PLM. Phosphomimetic and non-phosphorylatable PLM are plotted in red. $\mathrm{N} \geq 4$ biological replicates. 


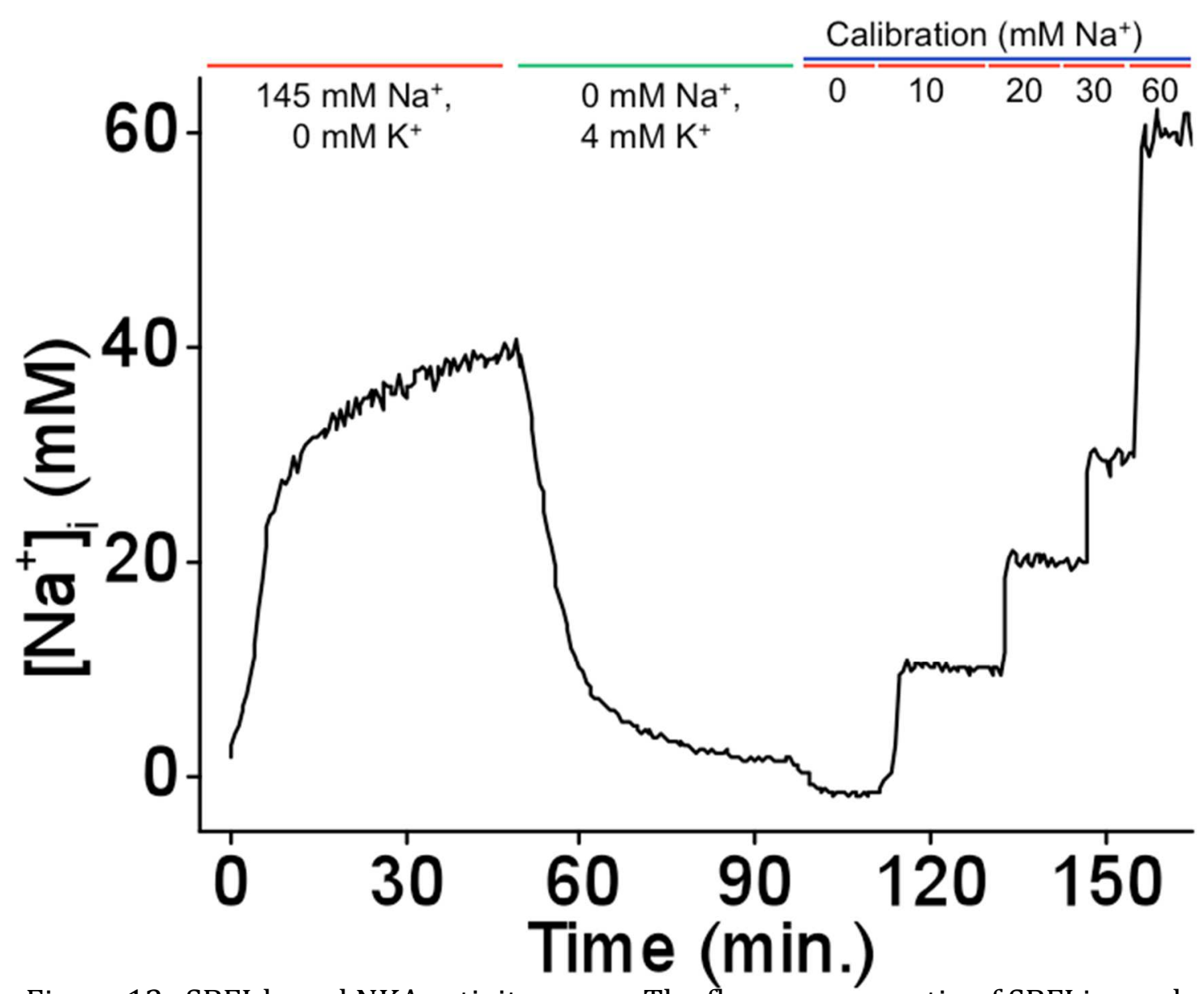

Figure 12. SBFI-based NKA activity assay. The fluorescence ratio of SBFI is used as an index of $\left[\mathrm{Na}^{+}\right]$i over time. First, cells are loaded with $\mathrm{Na}^{+}$and then NKA is activated by adding $\mathrm{K}^{+}$to the external bath solution. The fluorescence signal is then calibrated using solutions of known $\left[\mathrm{Na}^{+}\right]$i (see right-hand portion of figure). 


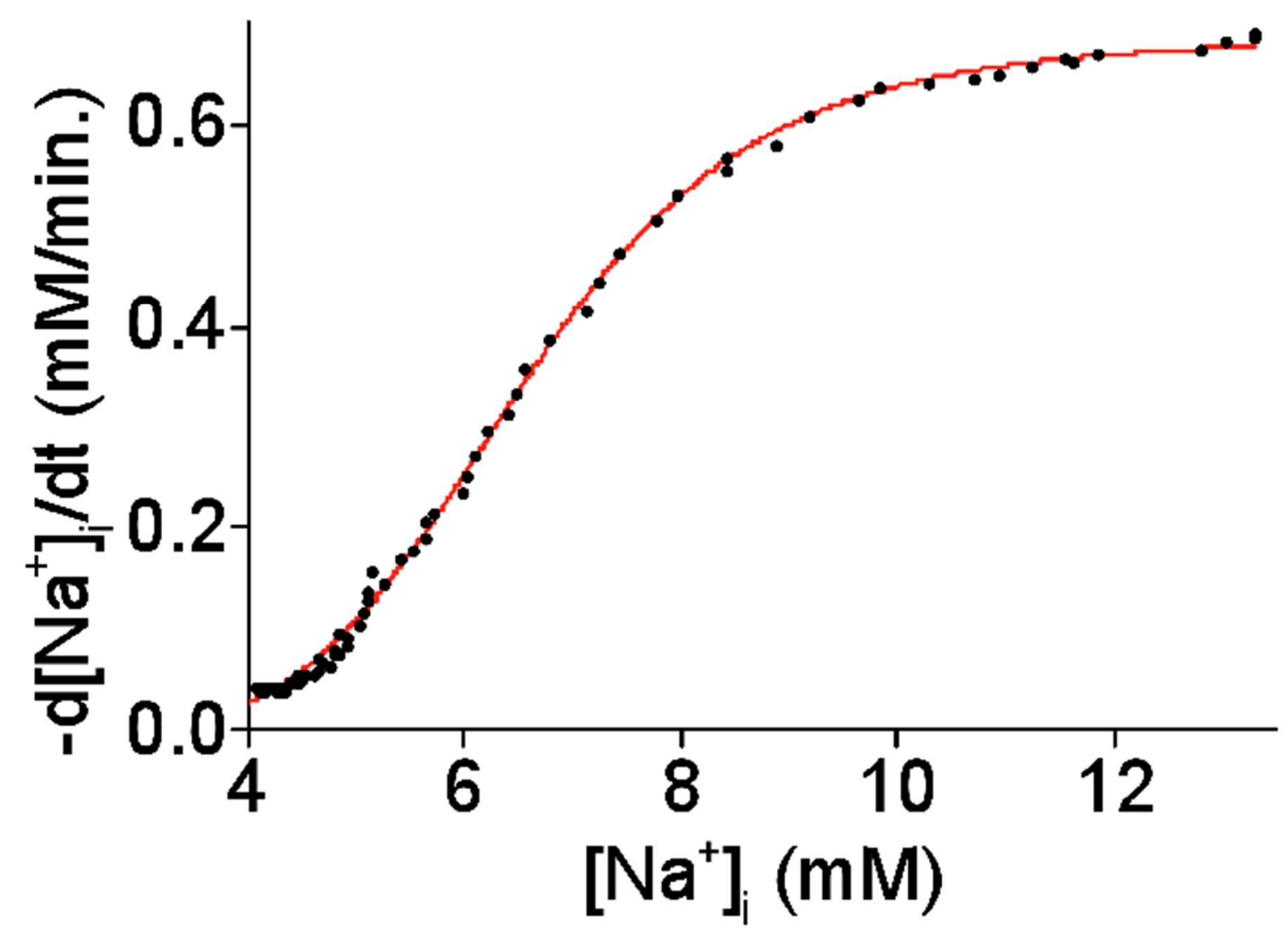

Figure 13. Ideal NKA activity curve derived from SBFI assay. The activity of NKA is calculated by taking the negative of the first derivative of the $\mathrm{Na}^{+}-$ extrusion portion of the SBFI assay data, and plotting against $\left[\mathrm{Na}^{+}\right]$i. This curve can then be fit with a Hill function in order to calculate the K0.5 value, or the affinity of NKA for $\mathrm{Na}^{+}$. 




Figure 14. Typical NKA activity curve derived from SBFI assay. Oftentimes, the activity curve derived from the SBFI assay failed to saturate. Without saturation, the $\mathrm{K}_{0.5}$ cannot be calculated, and therefore the effect of PLM mutants on the $\mathrm{Na}^{+}$affinity of NKA is difficult to assess. 


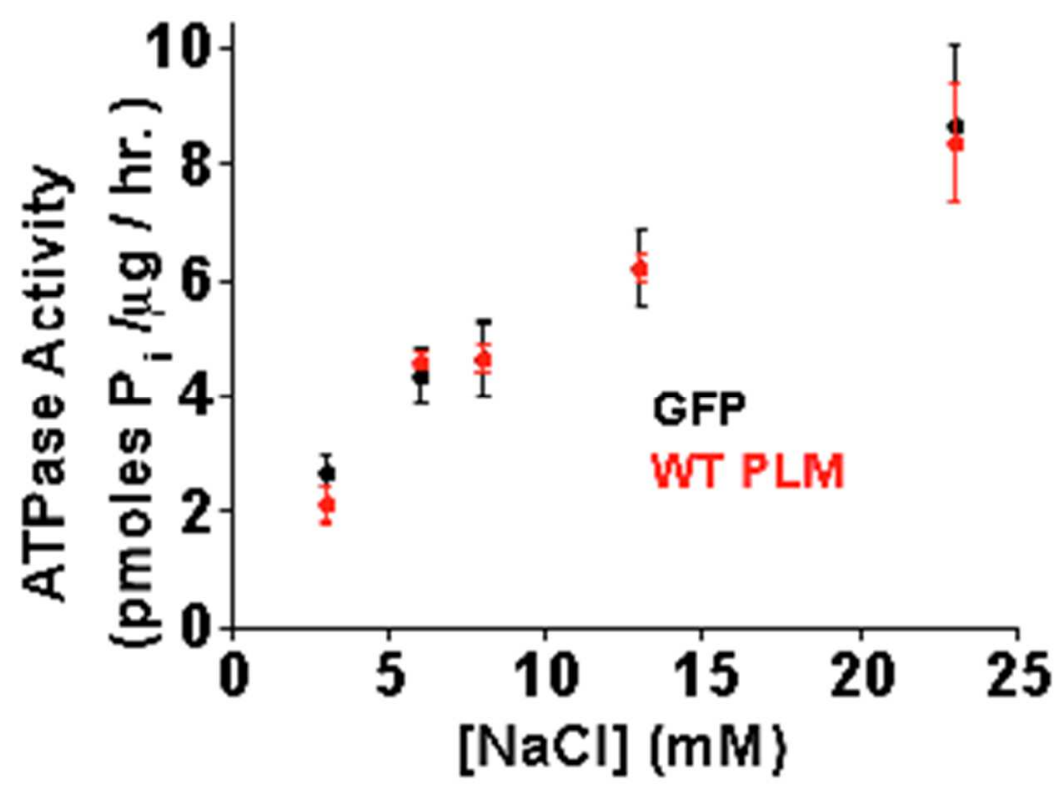

Figure 15. Ouabain-sensitive ATPase activity of membrane preparations. In order to measure NKA activity in HEK cells overexpressing WT PLM, ouabainsensitive ATPase activity was calculated over a range of $\mathrm{Na}^{+}$concentrations and was compared to cells expressing GFP as a control. While the activity increased with increasing $\left[\mathrm{Na}^{+}\right]$, there was no significant difference between WT PLM and GFP at any $\left[\mathrm{Na}^{+}\right]$. 




Figure 16. Exogenous expression of PLM-Citrine in a myocyte. A rabbit ventricular myocyte was infected with adenovirus used to express PLM-Citrine. The protein is synthesized in the SR and trafficked to the sarcolemma and Ttubules, as evidenced by co-localization with WGA Alexa Fluor 594. 

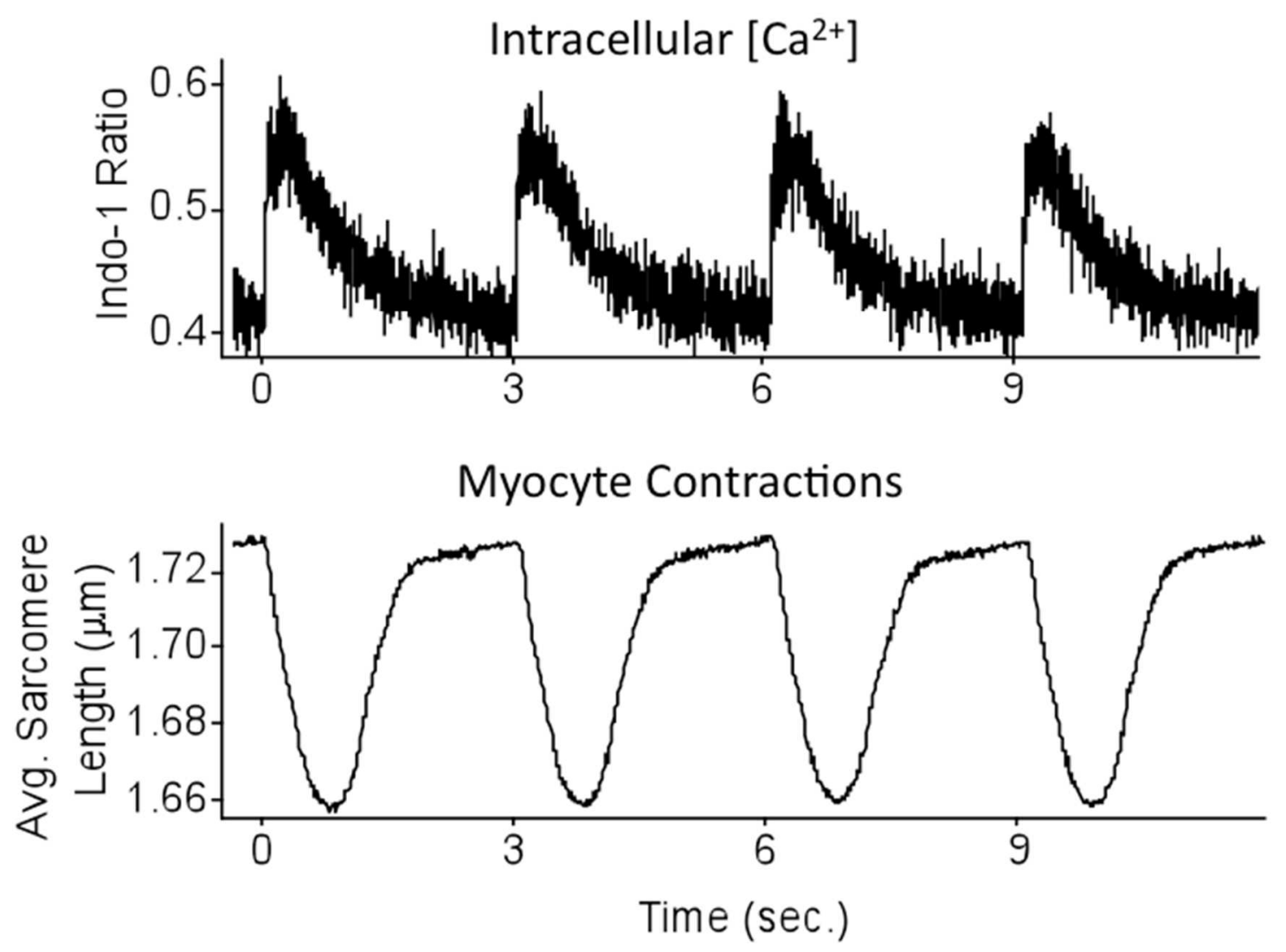

Figure 17. Examples of myocyte assay output. As the cardiomyocytes are paced, $\left[\mathrm{Ca}^{2+}\right] \mathrm{i}$ is measured over time (top) and is displayed as the fluorescence ratio of Indo-1 dye. Simultaneously, cell shortening is measured by calculating the average sarcomere length over time (bottom). About 10 transients are measured for each cell and then averaged together. 

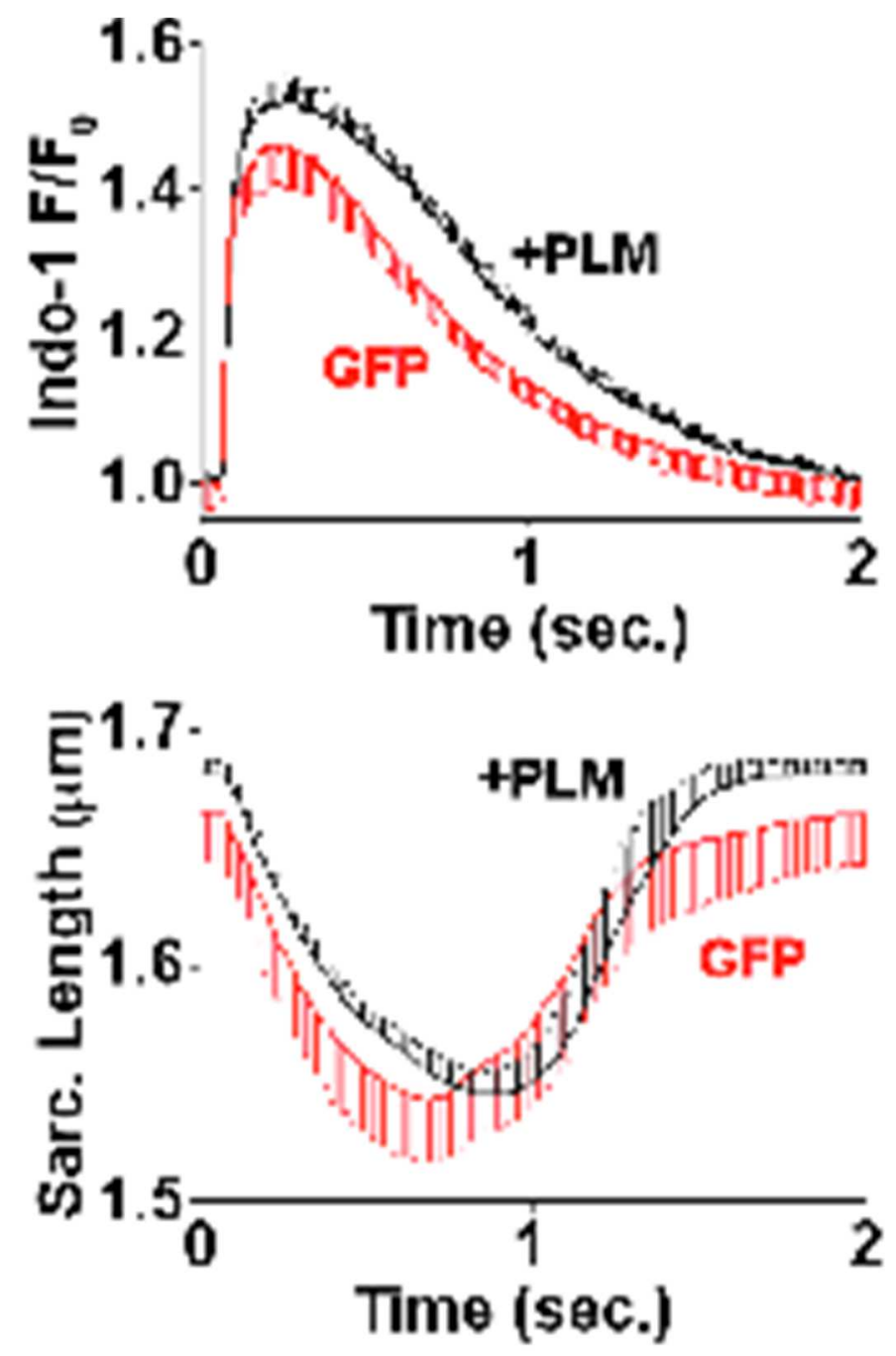

Figure 18. Functional myocyte data for WT PLM versus GFP. Averaged $\mathrm{Ca}^{2+}$ transients for myocytes expressing WT PLM (black, top) versus GFP (red) are plotted as the normalized fluorescence ratio of Indo- 1 over time, \pm SEM. The corresponding myocyte contractions are displayed as averaged sarcomere lengths over time, \pm SEM (bottom). $\mathrm{N} \geq 5$ cells. 

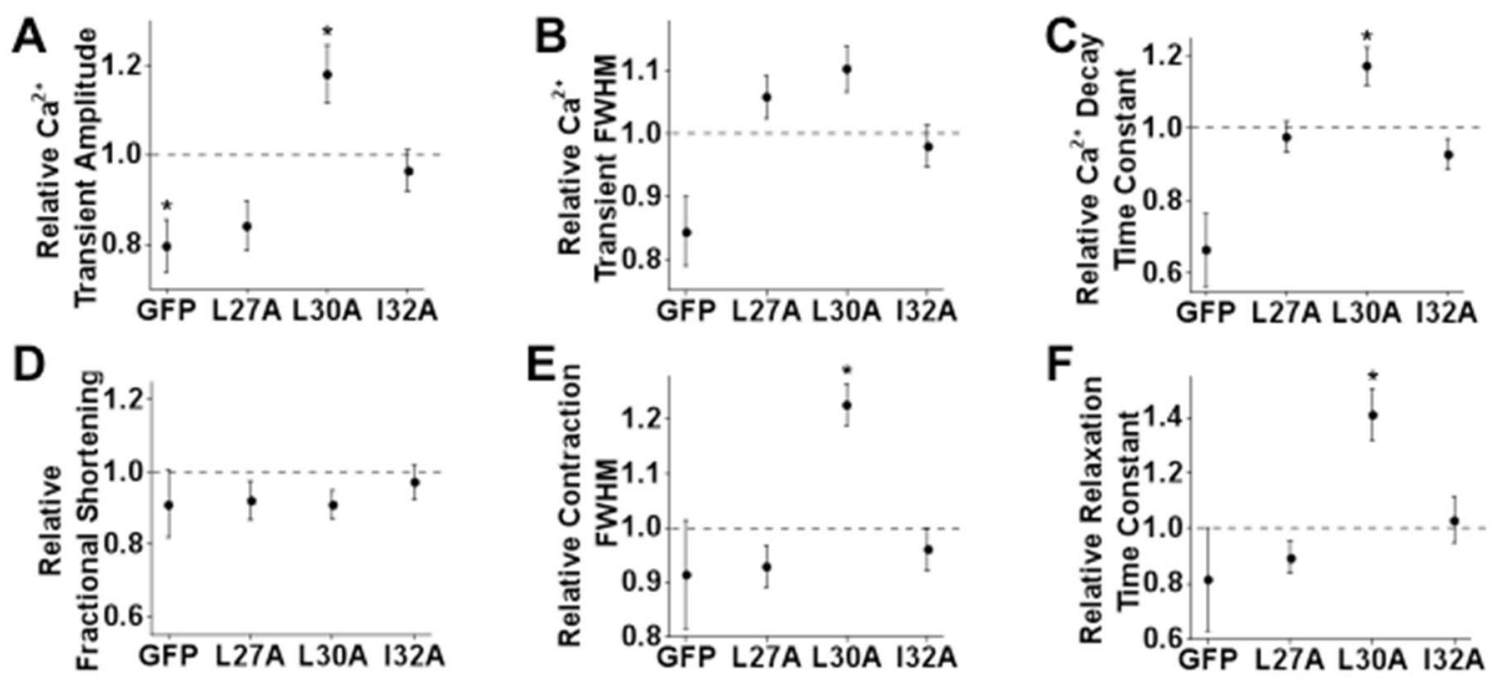

Figure 19. Functional effects of PLM mutants in myocytes. Averaged $\mathrm{Ca}^{2+}$ transient amplitude (A), $\mathrm{Ca}^{2+}$ transient full width at half maximum (B), $\mathrm{Ca}^{2+}$ decay time constant (C), fractional shortening (D), full width at half maximum for cell contractions (E), and cell relaxation time constant (F) \pm SEM for GFP, L27A, L30A, and I32A PLM normalized to WT (represented by a dashed line). *p $<0.05$ compared to WT. $\mathrm{N} \geq 5$ cells. 

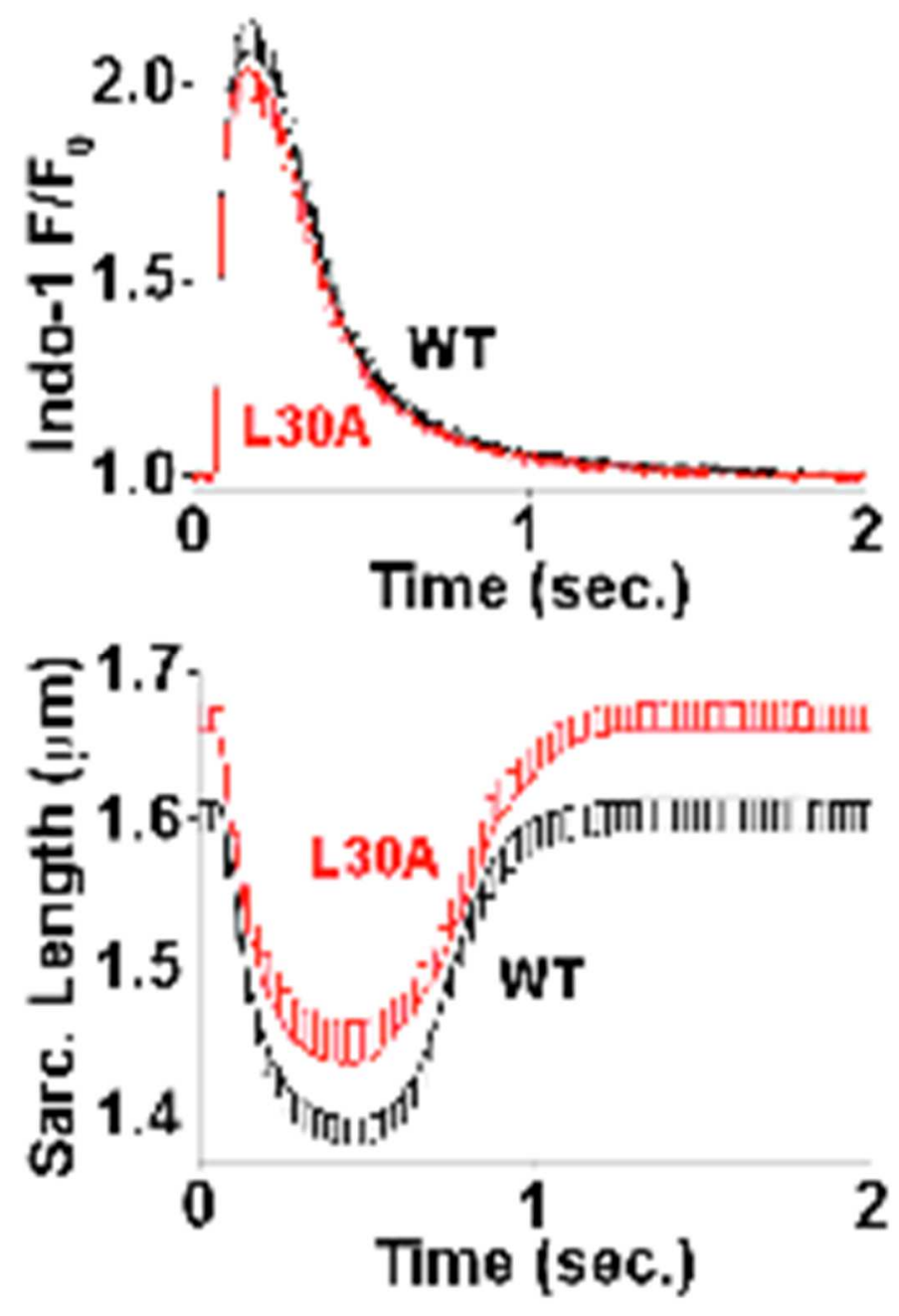

Figure 20. WT- versus L30A-expressing myocytes in the presence of isoproterenol. Averaged $\mathrm{Ca}^{2+}$ transients for myocytes expressing WT PLM (black, top) versus L30A (red) are plotted as the normalized fluorescence ratio of Indo- 1 over time, \pm SEM. The corresponding myocyte contractions are displayed as averaged sarcomere lengths over time, \pm SEM (bottom). $\mathrm{N}=38$ cells from 4 different rabbits. 


\begin{tabular}{|c|c|c|c|c|c|}
\hline Parameter & & WT & & L30A & P-Value \\
\hline Baseline Indo-1 & & 0.444 & & 0.431 & \\
\hline Ratio & \pm & 0.008 & \pm & 0.003 & 0.139 \\
\hline Peak Indo-1 & & 0.61 & & 0.61 & \\
\hline Ratio & \pm & 0.01 & \pm & 0.01 & 0.682 \\
\hline Transient & & 0.22 & & 0.26 & \\
\hline Amplitude & \pm & 0.01 & \pm & 0.01 & 0.036 \\
\hline Transient Amplitude & & 37 & & 42 & \\
\hline (\% of Baseline) & \pm & 2 & \pm & 2 & 0.124 \\
\hline Departure Velocity & & 7.1 & & 7.7 & \\
\hline$\left(\mathrm{sec}^{-1}\right)$ & \pm & 0.4 & \pm & 0.4 & 0.331 \\
\hline Time to $10 \%$ & & 0.080 & & 0.100 & \\
\hline Peak (sec.) & \pm & 0.008 & \pm & 0.009 & 0.094 \\
\hline Time to $50 \%$ & & 0.037 & & 0.040 & \\
\hline Peak (sec.) & \pm & 0.001 & \pm & 0.002 & 0.231 \\
\hline Time to $90 \%$ & & 0.093 & & 0.092 & \\
\hline Peak (sec.) & \pm & 0.005 & \pm & 0.006 & 0.915 \\
\hline Time to Peak & & 0.20 & & 0.23 & \\
\hline (sec.) & \pm & 0.01 & \pm & 0.01 & 0.193 \\
\hline Return Velocity & & -0.30 & & -0.30 & \\
\hline$\left(\mathrm{sec}^{-1}\right)$ & \pm & 0.02 & \pm & 0.02 & 0.940 \\
\hline Time to $10 \%$ & & 0.43 & & 0.46 & \\
\hline Baseline (sec.) & \pm & 0.02 & \pm & 0.03 & 0.387 \\
\hline Time to $50 \%$ & & 0.81 & & 0.89 & \\
\hline Baseline (sec.) & \pm & 0.03 & \pm & 0.03 & 0.053 \\
\hline Time to $90 \%$ & & 1.42 & & 1.52 & \\
\hline Baseline (sec.) & \pm & 0.04 & \pm & 0.02 & 0.027 \\
\hline Full Width at & & 0.77 & & 0.85 & \\
\hline Half Maximum (sec.) & \pm & 0.03 & \pm & 0.03 & 0.063 \\
\hline $\mathrm{Ca}^{7+}$ Decay Time & & 1.02 & & 1.19 & \\
\hline Constant (sec.) & \pm & 0.07 & \pm & 0.05 & 0.045 \\
\hline
\end{tabular}

Figure 21. $\mathrm{Ca}^{2+}$ transient data for WT versus L30A-expressing myocytes. Data are displayed as means \pm SEM. p-values from Student's T-test are listed. $N=38$ cells from 4 different rabbits. 


\begin{tabular}{|c|c|c|c|c|c|}
\hline Parameter & & WT & & L30A & P-Value \\
\hline Baseline Sarcomere & & 1.714 & & 1.675 & \\
\hline Length $(\mu \mathrm{m})$ & \pm & 0.007 & \pm & 0.006 & $<0.001$ \\
\hline Length at Peak & & 1.584 & & 1.559 & \\
\hline Contraction $(\mu \mathrm{m})$ & \pm & 0.009 & \pm & 0.006 & 0.023 \\
\hline Change in Length & & 0.130 & & 0.116 & \\
\hline$(\mu \mathrm{m})$ & \pm & 0.006 & \pm & 0.005 & 0.086 \\
\hline Fractional Shortening & & 7.6 & & 6.9 & \\
\hline$(\%)$ & \pm & 0.4 & \pm & 0.3 & 0.148 \\
\hline Contraction Velocity & & -0.51 & & -0.37 & \\
\hline$(\mu \mathrm{m} / \mathrm{sec})$ & \pm & 0.04 & \pm & 0.03 & 0.007 \\
\hline Time to $10 \%$ & & 0.072 & & 0.085 & \\
\hline Peak (sec.) & \pm & 0.004 & \pm & 0.008 & 0.161 \\
\hline Time to $50 \%$ & & 0.201 & & 0.233 & \\
\hline Peak (sec.) & \pm & 0.009 & \pm & 0.009 & 0.013 \\
\hline Time to $90 \%$ & & 0.47 & & 0.53 & \\
\hline Peak (sec.) & \pm & 0.02 & \pm & 0.02 & 0.017 \\
\hline Time to Peak & & 0.68 & & 0.81 & \\
\hline (sec.) & \pm & 0.03 & \pm & 0.02 & 0.001 \\
\hline Relaxation Velocity & & 0.61 & & 0.39 & \\
\hline$(\mu \mathrm{m} / \mathrm{sec})$. & \pm & 0.08 & \pm & 0.05 & 0.018 \\
\hline Time to $10 \%$ & & 0.84 & & 1.02 & \\
\hline Baseline (sec.) & \pm & 0.03 & \pm & 0.03 & $<0.001$ \\
\hline Time to $50 \%$ & & 1.00 & & 1.22 & \\
\hline Baseline (sec.) & \pm & 0.04 & \pm & 0.03 & $<0.001$ \\
\hline Time to $90 \%$ & & 1.22 & & 1.45 & \\
\hline Baseline (sec.) & \pm & 0.05 & \pm & 0.03 & $<0.001$ \\
\hline Full Width at & & 0.80 & & 0.99 & \\
\hline Half Maximum (sec.) & \pm & 0.04 & \pm & 0.03 & $<0.001$ \\
\hline Relaxation Time & & 0.40 & & 0.56 & \\
\hline Constant (sec.) & \pm & 0.03 & \pm & 0.04 & 0.002 \\
\hline
\end{tabular}

Figure 22. Myocyte contraction data for WT versus L30A-expressing myocytes. Data are displayed as means \pm SEM. p-values from Student's T-test are listed. N=38 cells from 4 different rabbits. 


\section{CHAPTER FOUR}

\section{POTENTIAL THERAPEUTICS FOR HEART FAILURE}

The goal of these experiments was to test the hypothesis that alanine substitution of PLM TM domain residues would destabilize PLM tetramers, leading to increased PLM-NKA binding, increased inhibition of NKA activity, and increased cardiac contractility that is reversible with $\beta$-adrenergic stimulation. This hypothesis was based on several previous observations. First, Kimura et al. demonstrated that alanine substitution of TM domain residues of PLB resulted in decreased PLB oligomerization and increased binding to and inhibition of SERCA (Kimura et al., 1997). Second, the Robia lab and others observed that phosphorylation of PLM relieved inhibition of NKA and increased PLM oligomerization (Bossuyt et al., 2006; Despa et al., 2005; Han et al., 2006; Q. Song et al., 2011) (therefore it was plausible that decreasing PLM-PLM binding would lead to increased PLM-NKA binding, and that this would be reversible with phosphorylation). Third, cardiac glycosides are known to inhibit NKA, leading to a positive inotropic effect (Bers, 2002; Hauptman \& Kelly, 1999). The results shown in the previous chapter, however, only partially support the hypothesis.

The anisotropy experiments demonstrated that for most of the TM domain PLM residues, alanine substitution either had no effect, or caused increased PLMPLM binding (Figure 9). One mutant, L30A, did show a large decrease in PLM-PLM 
binding (increased $\mathrm{K}_{\mathrm{D}} 1$ ). This was matched by an increase in binding to NKA (decreased $\mathrm{K}_{\mathrm{D}} 2$ ), as measured by acceptor sensitization FRET. But while L30A conformed to the hypothesis, most of the other mutants did not. Surprisingly, many showed increased PLM-NKA binding regardless of the effect on PLM oligomerization (see Figure 9). This suggests that PLM oligomerization is not the sole determinant of PLM-NKA binding. Shattock and co-workers reported the existence of a pool of PLM that does not interact with NKA (Wypijewski et al., 2013). It is possible that some of the mutants tested in my study are affecting the NKA-interacting and noninteracting pools of PLM separately. Further studies are needed to elucidate the function of the NKA-independent pool and how PLM mutation affects that function. Still, the goal of the FRET screen was to identify mutants that increased PLM-NKA binding, and then to test those mutants for functional effects. I chose L27A, L30A, and I32A as the initial candidates.

As described in the previous chapter, all attempts to measure the effect of PLM mutation on NKA activity ultimately were unsuccessful. However, the cardiomyocyte contractility and $\mathrm{Ca}^{2+}$ handling assay worked much better (in that it yielded reproducible results). I observed that overexpression of WT PLM increased the amplitude of the $\mathrm{Ca}^{2+}$ transient and increased the decay constant (tau) compared to GFP control (Figure 19). This mimicked the effect of ouabain, a cardiac glycoside, on isolated cardiomyocytes (Altamirano et al., 2006; Bers, 1987; 2002; Bers \& Bridge, 1988). While I did not observe an increase in fractional shortening, this is possibly due to the fact that the myocytes were unloaded, and so increased 
contractility manifested as an increase in the duration of the contraction, rather than an increase in shortening.

The fact that we observed these changes with WT PLM overexpression suggests that in rabbits, NKA is not saturated by endogenous PLM binding. In contrast, PLB-overexpressing rabbits had no observable phenotype, indicating that SERCA is likely saturated by endogenous PLB (Waggoner et al., 2009). Therefore, while NKA and SERCA share many characteristics (which partly led to the central hypothesis of the studies described here) they also have important differences, and the properties of one cannot reliably be predicted based on the observed properties of the other.

As in rabbits, it is likely that NKA is not saturated by endogenous PLM in humans either, since PLM is known to be basally phosphorylated in human hearts (El-Armouche et al., 2011). This underscores the potential for overexpression of WT PLM in humans to increase PLM-NKA binding, possibly leading to increased NKA inhibition and increased contractility.

L30A PLM increased the amplitude of the $\mathrm{Ca}^{2+}$ transient and the decay constant compared to WT overexpression. It also increased the duration of the contraction. These results suggest that for L30A, increased PLM-NKA binding led to increased inhibiton of NKA, although I was unable to test that directly. In contrast, for gain-of-NKA-binding mutants L27A and I32A, no differences in comparison to WT overexpression were observed. This indicates that increasing PLM-NKA binding does not necessarily mean increased NKA inhibition. Still, the rationale of testing 
gain-of-binding mutants for functional effects is logical, and it resulted in the discovery of L30A as a positively inotropic mutant.

After $\beta$-adrenergic stimulation, no detectable differences between L30A and WT PLM were observed, suggesting that the effects of L30A may be reversible. This is further supporting evidence for the idea that L30A PLM could be used in a therapeutic approach for the treatment of $\mathrm{HF}$, and that this therapy could be superior to cardiac glycosides. In Figure 23, I have contrasted these pharmacological and physiological approaches to inhibiting NKA and increasing cardiac contractility. Glycosides inhibit a fraction of the NKA pumps, leading to increased $\left[\mathrm{Na}^{+}\right]_{i}$ and inhibition of $\mathrm{Ca}^{2+}$ extrusion by NCX. This increases $\mathrm{SR} \mathrm{Ca}^{2+}$ load and cardiac contractility. However, $\left[\mathrm{Na}^{+}\right]_{\mathrm{i}}$ is already elevated in $\mathrm{HF}$ (Despa et al., 2002; Piacentino et al., 2003), and $\left[\mathrm{Na}^{+}\right]$and $\mathrm{SR} \mathrm{Ca}^{2+}$ overload can cause arrhythmias. This can only be prevented by careful titration of the glycoside dose, because inhibition of NKA by glycosides is not dynamically regulated in response to adrenaline. In contrast, the effect of superinhibition of NKA by PLM may be reversible; the $\mathrm{Ca}^{2+}$ transients and myocyte contractions of cells expressing WT versus L30A PLM converged following $\beta$-adrenergic stimulation. Additionally, while glycosides decrease the $\mathrm{V}_{\max }$ of NKA, increasing the risk of $\mathrm{Na}^{+}$-overload and arrhythmogenesis, PLM decreases the activity of NKA (by decreasing $\mathrm{Na}^{+}$affinity) but preserves $V_{\max }$ (Bossuyt et al., 2009; Despa et al., 2005; Han et al., 2009). This could mean a broader therapeutic window for superinhibityory PLM, because a rise in $\left[\mathrm{Na}^{+}\right]_{\mathrm{i}}$ would be limited by reserve NKA activity. Thus, both PLM phosphorylation 
and relief of NKA inhibition by high $\left[\mathrm{Na}^{+}\right]$i could provide physiological reversibility during stress.

If a PLM mutant like L30A were to be used in a clinical setting, the means of delivery to the patient would be through gene therapy. This involves the administration of a viral vector containing the DNA sequence for the protein to be expressed. Like with the cardiomyocyte experiments performed here, the L30A PLM gene could be inserted into an adenovirus genome, and then applied directly to the cardiac tissue using catheterization. This approach is currently being tested in a clinical trial for HF patients called CUPID. In HF, SERCA expression is known to be downregulated, and the goal of the gene therapy in CUPID is to rescue SERCA expression through exogenous delivery in an adenoviral vector (Jaski et al., 2009). So far, the results are encouraging (Zsebo et al., 2014).

These results notwithstanding, there are still many obstacles to overcome before gene therapy is approved for widespread use (Cotrim \& Baum, 2008). Questions remain as to how exogenous gene expression can be controlled longterm. Will the virus need to be reapplied? How can physicians turn off exogenous gene expression if it becomes too high? Answering these questions is beyond the scope of this current project. However, the evidence presented in this report suggests that if gene therapy becomes a viable treatment option in the future, exogenous delivery of WT or L30A PLM could help patients with HF.

The work presented here could be furthered by future experimentation. There are several other candidate mutants from the FRET screen, such as I23A or 
L33A, that have yet to be tested for effects on cardiomyocytes. Other mutants could be designed and tested as well, such as double or triple alanine substitutions that could yield a mutant with even greater effects than L30A. Ideally, mutants would be tested in an in vivo model of HF to see if exogenous expression actually relieves symptoms for animals, if overexpression is arrhythmogenic, or if PLM-NKA binding can be dynamically regulated to avoid arrhythmias. These later experiments would be necessary before PLM gene therapy could be pursued with humans. Furthermore, the experiments performed here employed the use of fluorescent protein fusion constructs. The effect of these fluorescent tags on protein function has not been directly tested, and therefore further testing with untagged PLM mutants should be performed.

In summary, the goal of this project was to test the hypothesis that mutation of TM domain PLM residues would lead to increased NKA inhibition and positive inotropy that would be physiologically reversible. Based on my results, I propose a new model where WT PLM overexpression results in increased binding to NKA and increased contractility; L30A PLM increases NKA binding and contractility even further, but there is no difference between WT- and L30A-expressing myocytes after $\beta$-adrenergic stimulation. 


\section{A Pharmacological NKA Inhibition B Physiological NKA Inhibition}
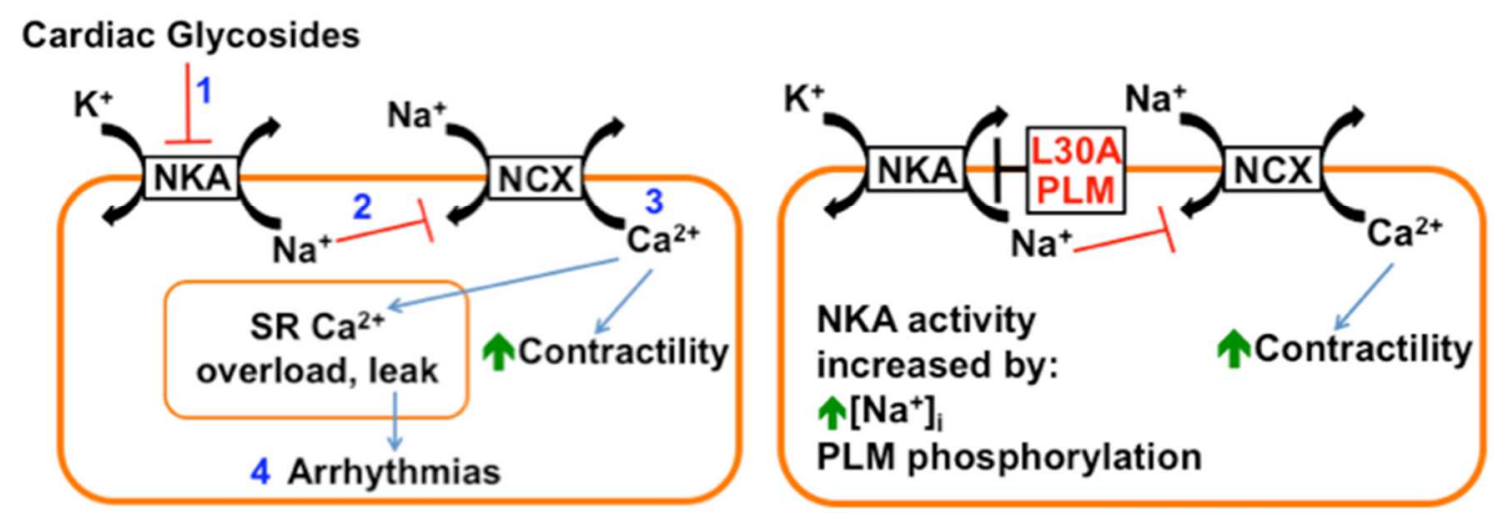

Figure 23. Pharmacological versus physiological inhibition of NKA. (A) Cardiac glycosides act by binding to and inhibiting the activity of NKA in the sarcolemma of cardiomyocytes (1). This leads to an increase in $\left[\mathrm{Na}^{+}\right] \mathrm{i}$, which inhibits the ability of NCX to extrude $\mathrm{Ca}^{2+}(2)$. As $\left[\mathrm{Ca}^{2+}\right]$ rises in the cytosol and in the SR (3), contractility is increased as intended. However, overdose of cardiac glycosides leads to overload of $\mathrm{Ca}^{2+}$ in the SR and leakage out of the SR, potentially causing an arrhythmia (4). (B) In this study, L30A PLM displayed increased binding to NKA (compared to WT PLM), and mimicked the effects of cardiac glycosides on isolated cardiomyocytes. Following $\beta$-adrenergic stimulation, which is known to cause PLM phosphorylation, there were no differences between WT- and L30A-overexpressing cells, suggesting that the effect of L30A mutation may be physiologically reversible. 


\section{BIBLIOGRAPHY}

Abrol, N., de Tombe, P. P., \& Robia, S. L. (2015). Acute Inotropic and Lusitropic Effects of Cardiomyopathic R9C Mutation of Phospholamban. Journal of Biological Chemistry. doi:10.1074/jbc.M114.630319

Ahlers, B. A., Zhang, X.-Q., Moorman, J. R., Rothblum, L. I., Carl, L. L., Song, J., et al. (2005). Identification of an endogenous inhibitor of the cardiac $\mathrm{Na}+/ \mathrm{Ca} 2+$ exchanger, phospholemman. The Journal of Biological Chemistry, 280(20), 19875-19882. doi:10.1074/jbc.M414703200

Altamirano, J., Li, Y., DeSantiago, J., Piacentino, V., Houser, S. R., \& Bers, D. M. (2006). The inotropic effect of cardioactive glycosides in ventricular myocytes requires Na+-Ca2+ exchanger function. The Journal of Physiology, 575(Pt 3), 845-854. doi:10.1113/jphysiol.2006.111252

Arystarkhova, E., Donnet, C., Muñoz-Matta, A., Specht, S. C., \& Sweadner, K. J. (2007). Multiplicity of expression of FXYD proteins in mammalian cells: dynamic exchange of phospholemman and gamma-subunit in response to stress. American Journal of Physiology. Cell Physiology, 292(3), C1179-91. doi:10.1152/ajpcell.00328.2006

Beevers, A. J., \& Kukol, A. (2006). Secondary structure, orientation, and oligomerization of phospholemman, a cardiac transmembrane protein. Protein Science : a Publication of the Protein Society, 15(5), 1127-1132. doi:10.1110/ps.051899406

Beevers, A. J., \& Kukol, A. (2007). Phospholemman Transmembrane Structure Reveals Potential Interactions with $\mathrm{Na}+\mathrm{K}+-\mathrm{ATPase}$. Journal of Biological Chemistry, 282(45), 32742-32748. doi:10.1074/jbc.M703676200

Berry, R. G., Despa, S., Fuller, W., Bers, D. M., \& Shattock, M. J. (2007). Differential distribution and regulation of mouse cardiac $\mathrm{Na}+\mathrm{K}+-\mathrm{ATPase}$ alpha1 and alpha2 subunits in T-tubule and surface sarcolemmal membranes. Cardiovascular Research, 73(1), 92-100. doi:10.1016/j.cardiores.2006.11.006

Bers, D. M. (1987). Mechanisms contributing to the cardiac inotropic effect of $\mathrm{Na}$ pump inhibition and reduction of extracellular $\mathrm{Na}$. The Journal of General Physiology, 90(4), 479-504. 
Bers, D. M. (2002). Cardiac excitation-contraction coupling. Nature, 415(6868), 198205. doi:10.1038/415198a

Bers, D. M., \& Bridge, J. H. (1988). Effect of acetylstrophanthidin on twitches, microscopic tension fluctuations and cooling contractures in rabbit ventricle. The Journal of Physiology, 404, 53-69.

Bidwell, P., Blackwell, D. J., Hou, Z., Zima, A. V., \& Robia, S. L. (2011). Phospholamban binds with differential affinity to calcium pump conformers. The Journal of Biological Chemistry. doi:10.1074/jbc.M111.266759

Blackman, S. M., Piston, D. W., \& Beth, A. H. (1998). Oligomeric state of human erythrocyte band 3 measured by fluorescence resonance energy homotransfer. Biophysical Journal, 75(2), 1117-1130. doi:10.1016/S0006-3495(98)77601-5

Boguslavskyi, A., Pavlović, D., Aughton, K., Clark, J. E., Howie, J., Fuller, W., \& Shattock, M. J. (2014). Cardiac hypertrophy in mice expressing unphosphorylatable phospholemman. Cardiovascular Research. doi:10.1093/cvr/cvu182

Bossuyt, J., Despa, S., Han, F., Hou, Z., Robia, S. L., Lingrel, J. B., \& Bers, D. M. (2009). Isoform specificity of the $\mathrm{Na} / \mathrm{K}-\mathrm{ATP}$ ase association and regulation by phospholemman. The Journal of Biological Chemistry, 284(39), 26749-26757. doi:10.1074/jbc.M109.047357

Bossuyt, J., Despa, S., Martin, J. L., \& Bers, D. M. (2006). Phospholemman phosphorylation alters its fluorescence resonance energy transfer with the $\mathrm{Na}$ /K-ATPase pump. The Journal of Biological Chemistry, 281(43), 32765-32773. doi:10.1074/jbc.M606254200

Cheung, J. Y., Rothblum, L. I., Moorman, J. R., Tucker, A. L., Song, J., Ahlers, B. A., et al. (2007). Regulation of cardiac $\mathrm{Na}+\mathrm{Ca} 2+$ exchanger by phospholemman. Annals of the New York Academy of Sciences, 1099, 119-134. doi:10.1196/annals.1387.004

Cheung, J. Y., Zhang, X.-Q., Song, J., Gao, E., Rabinowitz, J. E., Chan, T. O., \& Wang, J. (2010). Review Article: Phospholemman: A Novel Cardiac Stress Protein. Clinical and Translational Science, 3(4), 189-196. doi:10.1111/j.17528062.2010.00213.x

Cornelius, F., \& Mahmmoud, Y. A. (2003). Functional modulation of the sodium pump: the regulatory proteins "Fixit". News in Physiological Sciences : an International Journal of Physiology Produced Jointly by the International Union of Physiological Sciences and the American Physiological Society, 18, 119-124. 
Cotrim, A. P., \& Baum, B. J. (2008). Gene Therapy: Some History, Applications, Problems, and Prospects. Toxicologic Pathology, 36(1), 97-103. doi:10.1177/0192623307309925

Crambert, G., Fuzesi, M., Garty, H., Karlish, S., \& Geering, K. (2002). Phospholemman (FXYD1) associates with $\mathrm{Na}, \mathrm{K}-\mathrm{ATPase}$ and regulates its transport properties. Proceedings of the National Academy of Sciences of the United States of America, 99(17), 11476-11481. doi:10.1073/pnas.182267299

Despa, S., Bossuyt, J., Han, F., Ginsburg, K. S., Jia, L.-G., Kutchai, H., et al. (2005). Phospholemman-phosphorylation mediates the beta-adrenergic effects on $\mathrm{Na} / \mathrm{K}$ pump function in cardiac myocytes. Circulation Research, 97(3), 252-259. doi:10.1161/01.RES.0000176532.97731.e5

Despa, S., Islam, M. A., Pogwizd, S. M., \& Bers, D. M. (2002). Intracellular [Na+] and $\mathrm{Na}+$ pump rate in rat and rabbit ventricular myocytes. The Journal of Physiology, 539(Pt 1), 133-143.

Despa, S., Tucker, A. L., \& Bers, D. M. (2008). Phospholemman-mediated activation of $\mathrm{Na} / \mathrm{K}-\mathrm{ATPase}$ limits [Na]i and inotropic state during beta-adrenergic stimulation in mouse ventricular myocytes. Circulation, 117(14), 1849-1855. doi:10.1161/CIRCULATIONAHA.107.754051

Domeier, T. L., Blatter, L. A., \& Zima, A. V. (2009). Alteration of sarcoplasmic reticulum $\mathrm{Ca} 2+$ release termination by ryanodine receptor sensitization and in heart failure. The Journal of Physiology, 587(Pt 21), 5197-5209. doi:10.1113/jphysiol.2009.177576

Dostanic, I., Schultz, J. E. J., Lorenz, J. N., \& Lingrel, J. B. (2004). The alpha 1 isoform of $\mathrm{Na}, \mathrm{K}-\mathrm{ATPase}$ regulates cardiac contractility and functionally interacts and colocalizes with the $\mathrm{Na} / \mathrm{Ca}$ exchanger in heart. The Journal of Biological Chemistry, 279(52), 54053-54061. doi:10.1074/jbc.M410737200

El-Armouche, A., Wittköpper, K., Fuller, W., Howie, J., Shattock, M. J., \& Pavlović, D. (2011). Phospholemman-dependent regulation of the cardiac Na/K-ATPase activity is modulated by inhibitor-1 sensitive type-1 phosphatase. FASEB Journal : Official Publication of the Federation of American Societies for Experimental Biology, 25(12), 4467-4475. doi:10.1096/fj.11-184903

Figtree, G. A., Liu, C.-C., Bibert, S., Hamilton, E. J., Garcia, A., White, C. N., et al. (2009). Reversible oxidative modification: a key mechanism of $\mathrm{Na}+-\mathrm{K}+$ pump regulation. Circulation Research, 105(2), 185-193. doi:10.1161/CIRCRESAHA.109.199547 
Fuller, W., Howie, J., McLatchie, L. M., Weber, R. J., Hastie, C. J., Burness, K., et al. (2009). FXYD1 phosphorylation in vitro and in adult rat cardiac myocytes: threonine 69 is a novel substrate for protein kinase C. American Journal of Physiology. Cell Physiology, 296(6), C1346-55. doi:10.1152/ajpcell.00523.2008

Fuller, W., Tulloch, L. B., Shattock, M. J., Calaghan, S. C., Howie, J., \& Wypijewski, K. J. (2012). Regulation of the cardiac sodium pump. Cellular and Molecular Life Sciences : CMLS. doi:10.1007/s00018-012-1134-y

Guo, K., Wang, X., Gao, G., Huang, C., Elmslie, K. S., \& Peterson, B. Z. (2010). Amino acid substitutions in the FXYD motif enhance phospholemman-induced modulation of cardiac L-type calcium channels. AJP: Cell Physiology, 299(5), C1203-11. doi:10.1152/ajpcell.00149.2010

Han, F., Bossuyt, J., Despa, S., Tucker, A. L., \& Bers, D. M. (2006). Phospholemman phosphorylation mediates the protein kinase C-dependent effects on $\mathrm{Na}+/ \mathrm{K}+$ pump function in cardiac myocytes. Circulation Research, 99(12), 1376-1383. doi:10.1161/01.RES.0000251667.73461.fb

Han, F., Bossuyt, J., Martin, J. L., Despa, S., \& Bers, D. M. (2010). Role of phospholemman phosphorylation sites in mediating kinase-dependent regulation of the Na+-K+-ATPase. AJP: Cell Physiology, 299(6), C1363-9. doi:10.1152/ajpcell.00027.2010

Han, F., Tucker, A. L., Lingrel, J. B., Despa, S., \& Bers, D. M. (2009). Extracellular potassium dependence of the $\mathrm{Na}+\mathrm{K}+\mathrm{K}$-APase in cardiac myocytes: isoform specificity and effect of phospholemman. AJP: Cell Physiology, 297(3), C699-705. doi:10.1152/ajpcell.00063.2009

Hauptman, P. J., \& Kelly, R. A. (1999). Digitalis. Circulation, 99(9), 1265-1270.

Homma, N., Amran, M. S., Nagasawa, Y., \& Hashimoto, K. (2006). Topics on the $\mathrm{Na}+\mathrm{Ca} 2+$ exchanger: involvement of $\mathrm{Na}+\mathrm{Ca} 2+$ exchange system in cardiac triggered activity. Journal of Pharmacological Sciences, 102(1), 17-21.

Hou, Z., \& Robia, S. L. (2010). Relative affinity of calcium pump isoforms for phospholamban quantified by fluorescence resonance energy transfer. Journal of Molecular Biology, 402(1), 210-216. doi:10.1016/j.jmb.2010.07.023

Hou, Z., Hu, Z., Blackwell, D. J., Miller, T. D., Thomas, D. D., \& Robia, S. L. (2012). 2Color calcium pump reveals closure of the cytoplasmic headpiece with calcium binding. PLOS ONE, 7(7), e40369. doi:10.1371/journal.pone.0040369 
Hou, Z., Kelly, E. M., \& Robia, S. L. (2008). Phosphomimetic mutations increase phospholamban oligomerization and alter the structure of its regulatory complex. The Journal of Biological Chemistry, 283(43), 28996-29003. doi:10.1074/jbc.M804782200

Howie, J., Tulloch, L. B., Shattock, M. J., \& Fuller, W. (2013). Regulation of the cardiac $\mathrm{Na}(+)$ pump by palmitoylation of its catalytic and regulatory subunits. Biochemical Society Transactions, 41(1), 95-100. doi:10.1042/BST20120269

Ishizuka, N., Fielding, A. J., \& Berlin, J. R. (1996). Na pump current can be separated into ouabain-sensitive and -insensitive components in single rat ventricular myocytes. The Japanese Journal of Physiology, 46(3), 215-223.

James, P. F., Grupp, I. L., Grupp, G., Woo, A. L., Askew, G. R., Croyle, M. L., et al. (1999). Identification of a specific role for the $\mathrm{Na}, \mathrm{K}-\mathrm{ATPase}$ alpha 2 isoform as a regulator of calcium in the heart. Molecular Cell, 3(5), 555-563.

Jaski, B. E., Jessup, M. L., Mancini, D. M., Cappola, T. P., Pauly, D. F., Greenberg, B., et al. (2009). Calcium upregulation by percutaneous administration of gene therapy in cardiac disease (CUPID Trial), a first-in-human phase $1 / 2$ clinical trial. Journal of Cardiac Failure, 15(3), 171-181. doi:10.1016/j.cardfail.2009.01.013

Kelly, E. M., Hou, Z., Bossuyt, J., Bers, D. M., \& Robia, S. L. (2008). Phospholamban oligomerization, quaternary structure, and sarco(endo)plasmic reticulum calcium ATPase binding measured by fluorescence resonance energy transfer in living cells. The Journal of Biological Chemistry, 283(18), 12202-12211. doi:10.1074/jbc.M707590200

Khafaga, M., Bossuyt, J., Mamikonian, L., Li, J. C., Lee, L. L., Yarov-Yarovoy, V., et al. (2012). Na+/K+-ATPase E960 and phospholemman F28 are critical for their functional interaction. Proceedings of the National Academy of Sciences of the United States of America. doi:10.1073/pnas.1207866109

Kimura, Y., Kurzydlowski, K., Tada, M., \& MacLennan, D. H. (1997). Phospholamban inhibitory function is activated by depolymerization. The Journal of Biological Chemistry, 272(24), 15061-15064.

Laursen, M., Gregersen, J. L., Yatime, L., Nissen, P., \& Fedosova, N. U. (2015). Structures and characterization of digoxin- and bufalin-bound $\mathrm{Na}+, \mathrm{K}+$-ATPase compared with the ouabain-bound complex. Proceedings of the National Academy of Sciences of the United States of America, 201422997. doi:10.1073/pnas.1422997112 
Li, C., Grosdidier, A., Crambert, G., Horisberger, J.-D., Michielin, O., \& Geering, K. (2004). Structural and functional interaction sites between Na,K-ATPase and FXYD proteins. The Journal of Biological Chemistry, 279(37), 38895-38902. doi:10.1074/jbc.M406697200

Lindzen, M., Gottschalk, K.-E., Fuzesi, M., Garty, H., \& Karlish, S. J. D. (2006). Structural interactions between FXYD proteins and $\mathrm{Na}+\mathrm{K}+-\mathrm{ATPa} e$ : alpha/beta/FXYD subunit stoichiometry and cross-linking. The Journal of Biological Chemistry, 281(9), 5947-5955. doi:10.1074/jbc.M512063200

Lingrel, J. B., Argüello, J. M., Van Huysse, J., \& Kuntzweiler, T. A. (1997). Cation and cardiac glycoside binding sites of the Na,K-ATPase. Annals of the New York Academy of Sciences, 834, 194-206.

Lubarski, I., Pihakaski-Maunsbach, K., Karlish, S. J. D., Maunsbach, A. B., \& Garty, H. (2005). Interaction with the Na,K-ATPase and tissue distribution of FXYD5 (related to ion channel). The Journal of Biological Chemistry, 280(45), 3771737724. doi:10.1074/jbc.M506397200

McMurray, J. J. V., \& Pfeffer, M. A. (2005). Heart failure. Lancet, 365(9474), 18771889. doi:10.1016/S0140-6736(05)66621-4

Miller, J. R., Silver, P. J., \& Stull, J. T. (1983). The role of myosin light chain kinase phosphorylation in beta-adrenergic relaxation of tracheal smooth muscle. Molecular Pharmacology, 24(2), 235-242.

Moorman, J. R., Ackerman, S. J., Kowdley, G. C., Griffin, M. P., Mounsey, J. P., Chen, Z., et al. (1995). Unitary anion currents through phospholemman channel molecules. Nature, 377(6551), 737-740. doi:10.1038/377737a0

Mozaffarian, D., Benjamin, E. J., Go, A. S., Arnett, D. K., Blaha, M. J., Cushman, M., et al. (2015). Heart Disease and Stroke Statistics--2015 Update: A Report From the American Heart Association. Circulation, 131(4), e29-e322. doi:10.1161/CIR.0000000000000152

Mudd, J. O., \& Kass, D. A. (2008). Tackling heart failure in the twenty-first century. Nature, 451(7181), 919-928. doi:10.1038/nature06798

Neumann, J., Maas, R., Bokník, P., Jones, L. R., Zimmermann, N., \& Scholz, H. (1999). Pharmacological characterization of protein phosphatase activities in preparations from failing human hearts. The Journal of Pharmacology and Experimental Therapeutics, 289(1), 188-193. 
Pallikkuth, S., Blackwell, D. J., Hu, Z., Hou, Z., Zieman, D. T., Svensson, B., et al. (2013). Phosphorylated phospholamban stabilizes a compact conformation of the cardiac calcium-ATPase. Biophysical Journal, 105(8), 1812-1821. doi:10.1016/j.bpj.2013.08.045

Palmer, C. J., Scott, B. T., \& Jones, L. R. (1991). Purification and complete sequence determination of the major plasma membrane substrate for cAMP-dependent protein kinase and protein kinase $\mathrm{C}$ in myocardium. The Journal of Biological Chemistry, 266(17), 11126-11130.

Philipson, K. D., \& Nicoll, D. A. (2000). Sodium-calcium exchange: a molecular perspective. Annual Review of Physiology, 62, 111-133. doi:10.1146/annurev.physiol.62.1.111

Piacentino, V., Weber, C. R., Chen, X., Weisser-Thomas, J., Margulies, K. B., Bers, D. M., $\&$ Houser, S. R. (2003). Cellular basis of abnormal calcium transients of failing human ventricular myocytes. Circulation Research, 92(6), 651-658. doi:10.1161/01.RES.0000062469.83985.9B

Pogwizd, S. M., Sipido, K. R., Verdonck, F., \& Bers, D. M. (2003). Intracellular Na in animal models of hypertrophy and heart failure: contractile function and arrhythmogenesis. Cardiovascular Research, 57(4), 887-896.

Presti, C. F., Jones, L. R., \& Lindemann, J. P. (1985a). Isoproterenol-induced phosphorylation of a 15-kilodalton sarcolemmal protein in intact myocardium. The Journal of Biological Chemistry, 260(6), 3860-3867.

Presti, C. F., Scott, B. T., \& Jones, L. R. (1985b). Identification of an endogenous protein kinase $C$ activity and its intrinsic 15-kilodalton substrate in purified canine cardiac sarcolemmal vesicles. The Journal of Biological Chemistry, 260(25), 13879-13889.

Robia, S. L., Campbell, K. S., Kelly, E. M., Hou, Z., Winters, D. L., \& Thomas, D. D. (2007). Förster transfer recovery reveals that phospholamban exchanges slowly from pentamers but rapidly from the SERCA regulatory complex. Circulation Research, 101(11), 1123-1129. doi:10.1161/CIRCRESAHA.107.159947

Shattock, M. J., Ottolia, M., Bers, D. M., Blaustein, M. P., Boguslavskyi, A., Bossuyt, J., et al. (2015). $\mathrm{Na}+/ \mathrm{Ca} 2+$ exchange and $\mathrm{Na}+/ \mathrm{K}+$-ATPase in the heart. The Journal of Physiology, 593(6), 1361-1382. doi:10.1113/jphysiol.2014.282319

Silverman, B. D. Z., Fuller, W., Eaton, P., Deng, J., Moorman, J. R., Cheung, J. Y., et al. (2005). Serine 68 phosphorylation of phospholemman: acute isoform-specific activation of cardiac Na/K ATPase. Cardiovascular Research, 65(1), 93-103. 
doi:10.1016/j.cardiores.2004.09.005

Silverman, B. D. Z., Warley, A., Miller, J. I. A., James, A. F., \& Shattock, M. J. (2003). Is there a transient rise in sub-sarcolemmal $\mathrm{Na}$ and activation of $\mathrm{Na} / \mathrm{K}$ pump current following activation of I(Na) in ventricular myocardium? Cardiovascular Research, 57(4), 1025-1034.

SKOU, J. C. (1957). The influence of some cations on an adenosine triphosphatase from peripheral nerves. Biochimica Et Biophysica Acta, 23(2), 394-401.

Song, J., Gao, E., Wang, J., Zhang, X.-Q., Chan, T. O., Koch, W. J., et al. (2012). Constitutive overexpression of phosphomimetic phospholemman S68E mutant results in arrhythmias, early mortality, and heart failure: potential involvement of Na+/Ca2+ exchanger. AJP: Heart and Circulatory Physiology, 302(3), H770-81. doi:10.1152/ajpheart.00733.2011

Song, Q., Pallikkuth, S., Bossuyt, J., Bers, D. M., \& Robia, S. L. (2011). Phosphomimetic mutations enhance oligomerization of phospholemman and modulate its interaction with the Na/K-ATPase. The Journal of Biological Chemistry, 286(11), 9120-9126. doi:10.1074/jbc.M110.198036

Sweadner, K. J., \& Rael, E. (2000). The FXYD gene family of small ion transport regulators or channels: cDNA sequence, protein signature sequence, and expression. Genomics, 68(1), 41-56. doi:10.1006/geno.2000.6274

Takuwa, Y., Takuwa, N., \& Rasmussen, H. (1988). The effects of isoproterenol on intracellular calcium concentration. The Journal of Biological Chemistry, 263(2), 762-768.

Tulloch, L. B., Howie, J., Wypijewski, K. J., Wilson, C. R., Bernard, W. G., Shattock, M. J., \& Fuller, W. (2011). The inhibitory effect of phospholemman on the sodium pump requires its palmitoylation. Journal of Biological Chemistry, 286(41), 36020-36031. doi:10.1074/jbc.M111.282145

Waggoner, J. R., Ginsburg, K. S., Mitton, B., Haghighi, K., Robbins, J., Bers, D. M., \& Kranias, E. G. (2009). Phospholamban overexpression in rabbit ventricular myocytes does not alter sarcoplasmic reticulum Ca transport. American Journal of Physiology Heart and Circulatory Physiology, 296(3), H698-703. doi:10.1152/ajpheart.00272.2008

Wang, J., Zhang, X.-Q., Ahlers, B. A., Carl, L. L., Song, J., Rothblum, L. I., et al. (2006). Cytoplasmic tail of phospholemman interacts with the intracellular loop of the cardiac $\mathrm{Na}+\mathrm{Ca} 2+$ exchanger. The Journal of Biological Chemistry, 281(42), 32004-32014. doi:10.1074/jbc.M606876200 
Wang, X., Gao, G., Guo, K., Yarotskyy, V., Huang, C., Elmslie, K. S., \& Peterson, B. Z. (2010). Phospholemman modulates the gating of cardiac L-type calcium channels. Biophysical Journal, 98(7), 1149-1159. doi:10.1016/j.bpj.2009.11.032

Wypijewski, K. J., Howie, J., Reilly, L., Tulloch, L. B., Aughton, K. L., McLatchie, L. M., et al. (2013). A separate pool of cardiac phospholemman that does not regulate or associate with the sodium pump: multimers of phospholemman in ventricular muscle. Journal of Biological Chemistry. doi:10.1074/jbc.M113.460956

Yang, E. H., Shah, S., \& Criley, J. M. (2012). Digitalis toxicity: a fading but crucial complication to recognize. The American Journal of Medicine, 125(4), 337-343. doi:10.1016/j.amjmed.2011.09.019

Zal, T., \& Gascoigne, N. R. J. (2004). Photobleaching-Corrected FRET Efficiency Imaging of Live Cells. Biophysical Journal, 86(6), 3923-3939. doi:10.1529/biophysj.103.022087

Zhang, X.-Q., Ahlers, B. A., Tucker, A. L., Song, J., Wang, J., Moorman, J. R., et al. (2006). Phospholemman inhibition of the cardiac $\mathrm{Na}+\mathrm{Ca} 2+$ exchanger. Role of phosphorylation. The Journal of Biological Chemistry, 281(12), 7784-7792. doi:10.1074/jbc.M512092200

Zhang, X.-Q., Wang, J., Carl, L. L., Song, J., Ahlers, B. A., \& Cheung, J. Y. (2009). Phospholemman regulates cardiac $\mathrm{Na}+\mathrm{Ca} 2+$ exchanger by interacting with the exchanger's proximal linker domain. American Journal of Physiology. Cell Physiology, 296(4), C911-21. doi:10.1152/ajpcell.00196.2008

Zsebo, K., Yaroshinsky, A., Rudy, J. J., Wagner, K., Greenberg, B., Jessup, M., \& Hajjar, R. J. (2014). Long-term effects of AAV1/SERCA2a gene transfer in patients with severe heart failure: analysis of recurrent cardiovascular events and mortality. Circulation Research, 114(1), 101-108. doi:10.1161/CIRCRESAHA.113.302421 
VITA

Ryan Himes was born on May 28, 1984 to David and Diane Himes, and was raised in the western suburbs of Chicago, IL. He married Sarah Elizabeth Millikan on April 4, 2008. On June 8, 2013 they had their first child, a daughter named Mallory Lynn. Ryan received a B.S. in chemistry with an emphasis in biochemistry from Wheaton College in May of 2006. After graduating, his first job was as a research technician in the laboratory of Dr. John Callaci, at Loyola University Chicago.

Ryan joined the Integrated Program in Biomedical Sciences at Loyola University Chicago in August of 2010. The following year, he transferred to the Department of Cell and Molecular Physiology and joined the laboratory of Dr. Seth L. Robia where he studied the sodium-potassium ATPase and its regulatory protein, phospholemman. He received a predoctoral fellowship from the American Heart Association in the fall of 2014. 